\title{
LEANDRO MOLINA
}

\section{EFEITOS DO TREINAMENTO E DESTREINAMENTO FÍSICO SOBRE A MANUTENÇÃO DA MEMÓRIA E FUNCIONAMENTO DO SISTEMA COLINÉRGICO CENTRAL DE CAMUNDONGOS.}

\begin{abstract}
Dissertação apresentada ao Programa de Pós-Graduação em Farmacologia do Instituto de Ciências Biomédicas da Universidade de São Paulo, para obtenção do título de Mestre em Ciências
\end{abstract}




\title{
LEANDRO MOLINA
}

\section{EFEITOS DO TREINAMENTO E DESTREINAMENTO FÍSICO SOBRE A MANUTENÇÃO DA MEMÓRIA E FUNCIONAMENTO DO SISTEMA COLINÉRGICO CENTRAL DE CAMUNDONGOS.}

\author{
Dissertação apresentada ao Programa de \\ Pós-Graduação em Farmacologia do \\ Instituto de Ciências Biomédicas da \\ Universidade de São Paulo, para obtenção \\ do título de Mestre em Ciências \\ Área de concentração: Farmacologia \\ Orientadora: Profa. Dra. Tânia Araújo Viel \\ Versão original
}


DADOS DE CATALOGAÇÃO NA PUBLICAÇÃO (CIP)

Serviço de Biblioteca e Informação Biomédica do

Instituto de Ciências Biomédicas da Universidade de São Paulo

reprodução não autorizada pelo autor

Molina, Leandro.

Efeitos do treinamento e destreinamento físico sobre a manutenção da memória e funcionamento do sistema colinérgico central de camundongos / Leandro Molina. -- São Paulo, 2013.

Orientador: Profa. Dra. Tânia Araújo Viel.

Dissertação (Mestrado) - Universidade de São Paulo. Instituto de Ciências Biomédicas. Departamento de Farmacologia. Área de concentração: Farmacologia. Linha de pesquisa: Estudo de neurofarmacologia e envelhecimento.

Versão do título para o inglês: Physical effects of training and detraining on memory maintenance and the operation of the cholinergic central system of mice.

$\begin{array}{llll}\text { 1. Memória } & \text { 2. Destreinamento físico } & 3 \text {. Alfa } 7 & 4 . \text { BDNF }\end{array}$ 5. Treinamento físico I. Viel, Profa. Dra. Tânia Araújo II. Universidade de São Paulo. Instituto de Ciências Biomédicas. Programa de Pós-Graduação em Farmacologia III. Título. 
Candidato(a):

Título da Dissertação:

Orientador(a):
Leandro Molina.

Efeitos do treinamento e destreinamento físico sobre a manutenção da memória e funcionamento do sistema colinérgico central de camundongos.

Profa. Dra. Tânia Araújo Viel.

A Comissão Julgadora dos trabalhos de Defesa da Dissertação de Mestrado, em sessão pública realizada a considerou

\section{( ) Aprovado(a) \\ ( ) Reprovado(a)}

Examinador(a): Assinatura:

Nome:

Instituição:

Examinador(a): Assinatura:

Nome:

Instituição:

Presidente:

Assinatura:

Nome:

Instituição: 


\section{Certificado}

Declaro que o projeto intitulado "Efeitos do destreinamento sobre a manutenção da memória e funcionalidade do sistema colinérgico central de camundongos", sob responsabilidade do(a) Prof(a) $\operatorname{Dr}(a)$ Tânia Araújo Viel e do qual participam o(s) aluno(s) Leandro Molina e Danilo Mourelli e o(s) pesquisador(es) Fabiana de Sant'Anna Evangelista e Hudson de Sousa Buck está em acordo com os princípios éticos de experimentação animal, conforme a Lei Federal 11.794 de 08 de outubro de 2008 , e foi aprovado por este comitê, recebendo o protocolo 001/2013.

O presente certificado tem validade de dois anos.

São Paulo, 05 de abril de 2013.

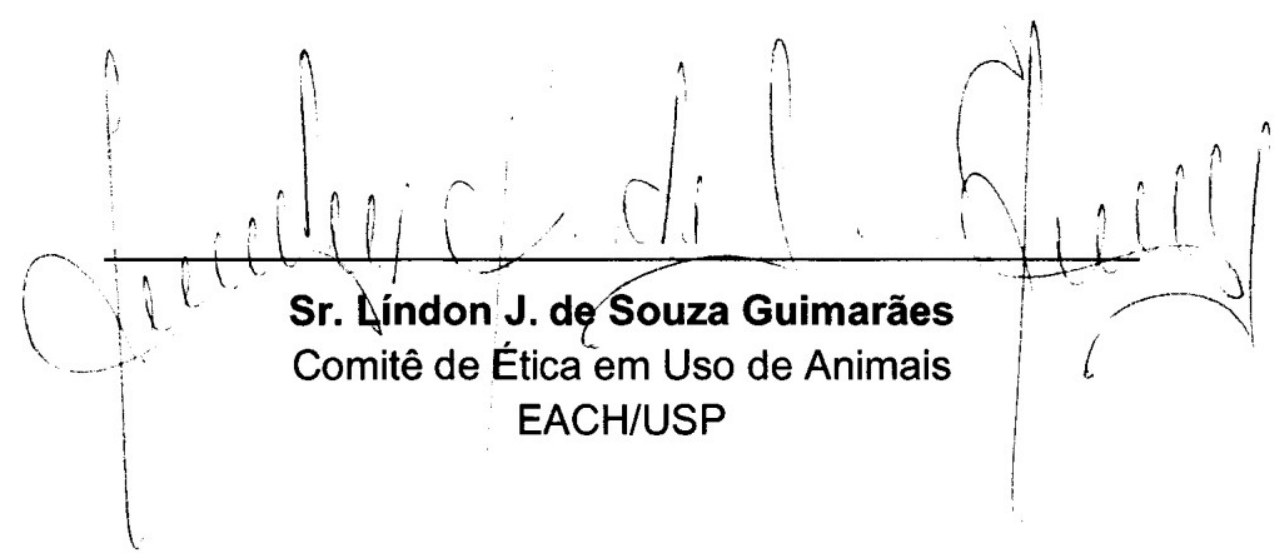


Aos meus pais, familiares e amigos pela dedicação, incentivo e apoio constante para a minha formação

Obrigado! 


\section{AGRADECIMENTOS}

Agradeço primeiramente aos meus pais, Zoca e Léia e minha tia Sula, por colaborarem com a minha formação, sempre me incentivando e apoiando minhas iniciativas, meu irmão Augusto por incentivar-me a continuar buscando meus sonhos, mesmo que isso tenha feito com que o nosso convívio fosse bem mais distante que o desejado.

Agradeço também aos meus colegas e minha orientadora Tânia Viel do Laboratório de Biomedicina e Biotecnologia da Escola de Artes, Ciências e Humanidades, por terem aberto as portas e concedido inestimável auxílio e amizade, ao Professor Cristóforo Scavone por acreditar em mim e me dar mais uma chance de terminar o que eu objetivei quando cheguei à USP, às secretárias Mônica e Camila, por me alertar sempre dos meus prazos e pelo profissionalismo impecável.

Agradeço também à Profa. Carolina Munhoz ICB/USP e ao Prof. Dr. Hudson Buck, Chefe do Departamento de Ciências Fisiológicas da Faculdade de Ciências Médicas da Santa Casa de São Paulo, por abrir as portas de seus respectivos laboratórios, para a realização de parte desse trabalho.

Gostaria de agradecer a minha melhor amiga Flávia, que é sem dúvida alguma a principal responsável por eu ter ingressado na pós-graduação e chegar ao final, mesmo depois de tudo que passamos juntos nesse processo.

Gostaria de mandar um salve, à todos os amigos da República Bacamarte, pelos anos e momentos incríveis que passei durante a minha formação, com certeza ficará na memória todos os bons momentos vividos.

Agradeço também a minha namorada Caroline pelo carinho e compreensão e que sem dúvida alguma me inspirou muito nessa reta final e me deu forças, motivação e exemplo para seguir adiante, mesmo com todos os empecilhos e dificuldade de um relacionamento à distância. Te amo. 
"Por que você quer tanto isto?

Porque disseram que eu não conseguiria"

(filme "Homens de Honra") 


\section{RESUMO}

MOLINA, L. Efeitos do treinamento e destreinamento físico sobre a manutenção da memória e funcionamento do sistema colinérgico central de camundongos. 2013. 51 f. Dissertação (Mestrado em Farmacologia) - Instituto de Ciências Biomédicas, Universidade de São Paulo, São Paulo, 2013.

Os processos da formação da memória envolvem aprendizagem, consolidação e recuperação de informações, além de diversos circuitos neuronais que incluem córtex, áreas hipocampais e amígdala. A formação da memória de longa duração ocorre a partir da formação da potenciação de longa duração (LTP - "long term potentiation") que é modulada, em algumas áreas, por diversos sistemas de neurotransmissores, entre eles o sistema colinérgico. Sabe-se que a atividade física aumenta a produção de neurotrofinas levando à melhora de estados patológicos como a depressão. Além do mais, por esse mesmo motivo, seus benefícios têm sido relacionados a uma melhora na função cognitiva. Por outro lado, já foi relatado que o destreinamento por duas semanas leva à reversão dos efeitos benéficos cardiovasculares, mas ainda há poucos trabalhos conclusivos relacionados aos efeitos sobre as funções cognitivas. Em estudo anterior, mostramos que o exercício físico crônico e moderado, realizado em esteira ergométrica, aumentou significativamente a evocação da memória de ratos pouco-responsivos ao condicionamento operante, avaliado em esquiva ativa. Esses animais apresentaram, também, aumento da densidade de receptores colinérgicos nicotínicos alfa7 em células piramidais da área CA1 do hipocampo e no núcleo accumbens. Os efeitos do destreinamento físico, entretanto, não foram avaliados. Esse projeto avalia os efeitos do treinamento e do destreinamento físico em piscina, sobre a manutenção da memória de longa duração de camundongos fêmeas. Foi observado que os animais treinados por quatro semanas mantiveram a memória da tarefa adquirida antes do início do treinamento, diferente dos animais do grupo sedentário. Os animais treinados foram separados em dois grupos - os que seriam mantidos em treinamento e os que seriam destreinados. Após mais duas semanas de observação, o grupo de animais destreinados perderam a memória da tarefa, diferente dos animais treinados. Ao término dos ensaios comportamentais, os cérebros foram isolados e congelados. Córtex, hipocampo, amígdala e estriado foram separados e preparados para os ensaios de western-blot para determinação da densidade de receptores nicotínicos alfa7 e da neurotrofina BDNF, que não demonstrou diferença significativa entre os grupos avaliados no trabalho.

Palavras-chave: Memória. Destreinamento físico. Alfa 7. BDNF. Treinamento Físico 


\begin{abstract}
MOLINA, L. Physical Effects of training and detraining on memory maintenance and operation of the central cholinergic system of mice. 2013. 51 p. Dissertation (Masters thesis in Pharmacology) -Instituto de Ciências Biomédicas, Universidade de São Paulo, São Paulo, 2013.
\end{abstract}

The processes of memory formation involves learning, consolidation and retrieval of information, besides several neuronal circuits that include the cortex, amygdala and hippocampal areas. The formation of long term memory occurs through the formation of long-term potentiation which is modulated in some areas by several neurotransmitter systems, including the cholinergic system. It is known that physical activity increases production of neurotrophins leading to improvement in disease states such as depression. Moreover, for the same reason, its benefits have been linked to an improvement in cognitive function. On the other hand, it has been reported that for two weeks detraining leads to the reversion of cardiovascular beneficial effects, but there are few studies related to the conclusive effect on cognitive functions. In a previous studies, we showed that chronic exercise and moderate, performed on a treadmill, significantly increased the evocation of the memory of non-responsive rats to operant conditioning, valued at active avoidance . These animals also showed increased density of alpha 7 nicotinic acetylcholine receptors in the pyramidal cells of CA1 area of the hippocampus and nucleus accumbens. The effects of physical detraining, however, were not evaluated. This project evaluates the effects of physical training and detraining on swimming on the maintenance of long-term memory of female mice. It has been observed that animals kept for four weeks trained memory task acquired before the start of training, animals of different sedentary group. The trained animals were separated into two groups those who would be kept in training and that would be untrained. After two more weeks of observation, the group of untrained animals have lost the memory of the task, differently from the trained animals. At the end of behavioral testing, the brains were isolated and frozen. Cortex, hippocampus, amygdala and striatum were separated and prepared for Western blot assays for evaluation of the density of alpha7 nicotinic receptors and the neurotrophin BDNF, which showed no significant difference among the groups at work.

Keywords: Memory. Physical Detraining. Alpha 7. BDNF. Physical Training. 


\section{LISTA DE ILUSTRAÇÕES}

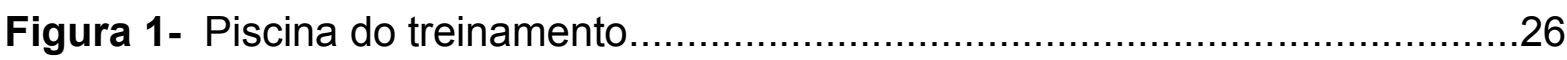

Figura 2- Deambulação e exploração vertical.....................................................31

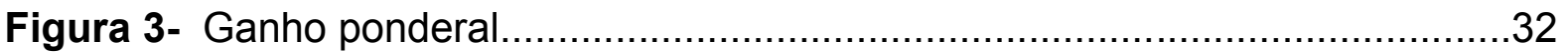

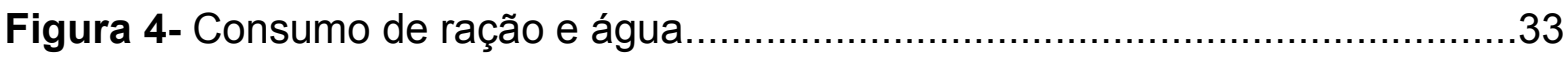

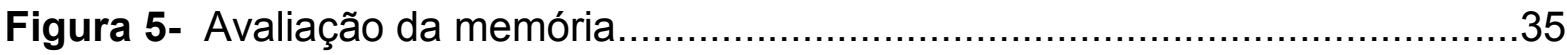

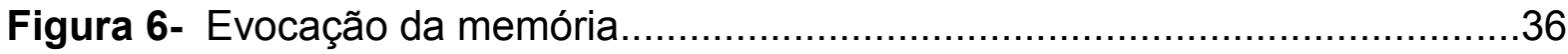

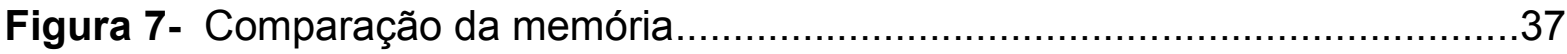

Figura 8- Determinação da densidade da neurotrofina BDNF...............................38

Figura 9- Curva de análise da concentração do receptor alfa 7 ............................39

Figura 10- Determinação da densidade do receptor alfa $7 \ldots \ldots \ldots \ldots \ldots \ldots \ldots \ldots \ldots \ldots \ldots \ldots . . .40$ 


\section{SUMÁRIO}

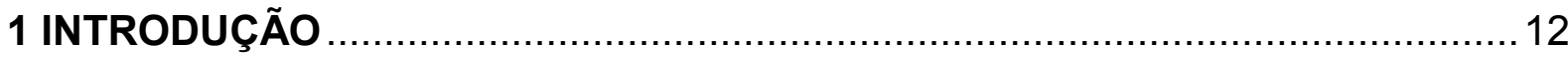

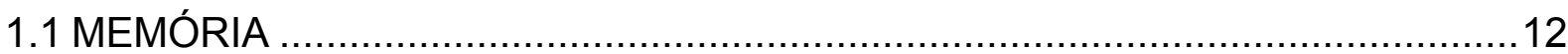

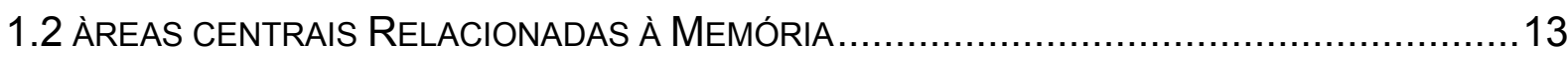

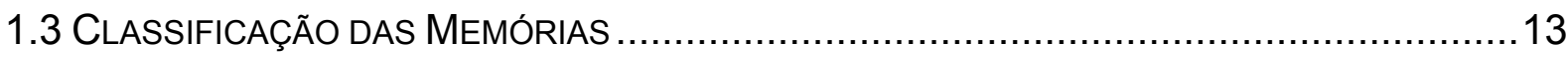

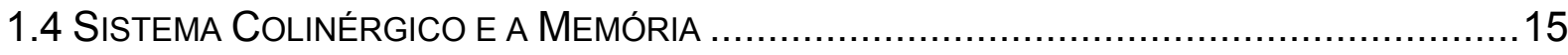

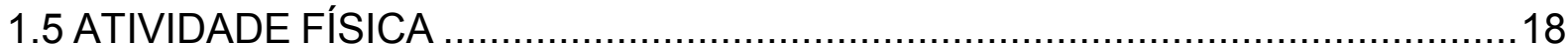

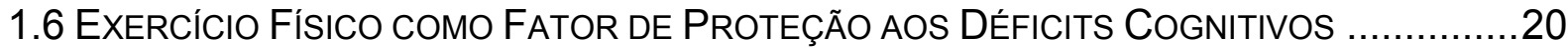

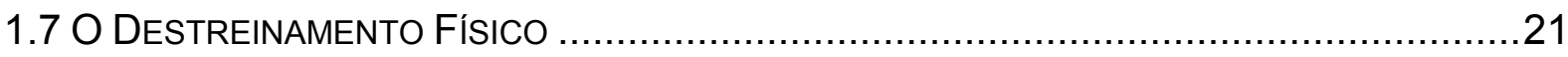

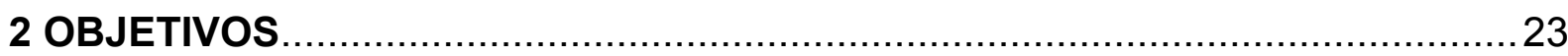

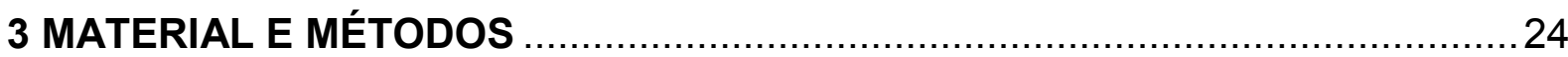

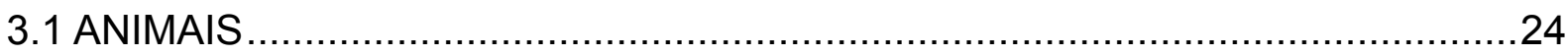

3.2 AVALIAÇÃO DA MEMÓRIA DE LONGA DURAÇÃO .....................................24

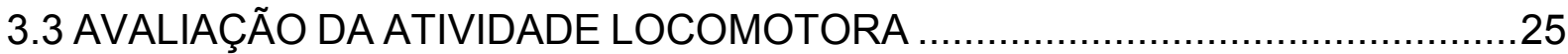

3.4 PROTOCOLO DE TREINAMENTO FÍSICO E DESTREINAMETO ....................25

3.5 AVALIAÇÃO DE PESO CORPORAL E CONSUMO DE ÁGUA E COMIDA .........27

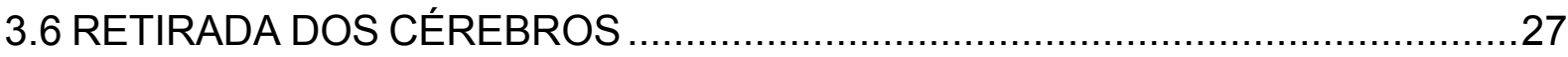

3.7 DETERMINAÇÃO DA DENSIDADE DO RECEPTOR ALFA 7, EM HIPOCAMPO PELO MÉTODO DE

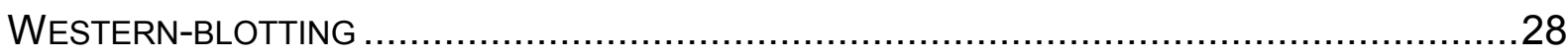

3.8 DETERMINAÇÃO DA DENSIDADE DA NEUROTROFINA BDNF EM HIPOCAMPO ..................28

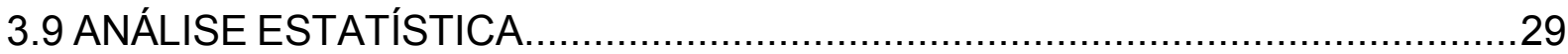

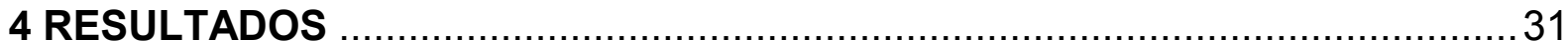

4.1 AVALIAÇÃO DA ATIVIDADE LOCOMOTORA ......................................... 31

4.2 AVALIAÇÃO DO PESO CORPORAL....................................................... 32

4.3 AVALIAÇÃO DO CONSUMO DE RAÇÃO E ÁGUA ........................................ 33

4.4 AVALIAÇÃO DA MEMÓRIA DE LONGA DURAÇÃO .....................................34

4.5 DETERMINAÇÃO DA DENSIDADE DA NEUROTROFINA BDNF EM HIPOCAMPO .................38

4.6 DETERMNAÇÃO DA DENSIDADE DO RECEPTOR ALFA 7 EM HIPOCAMPO .........................39

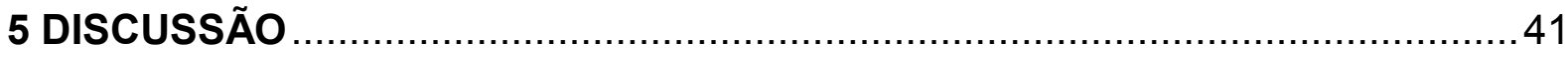

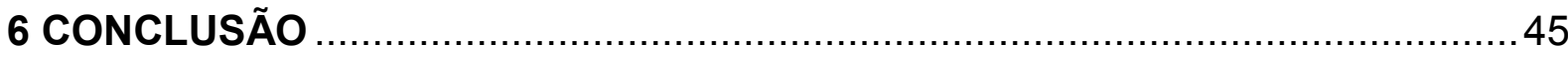

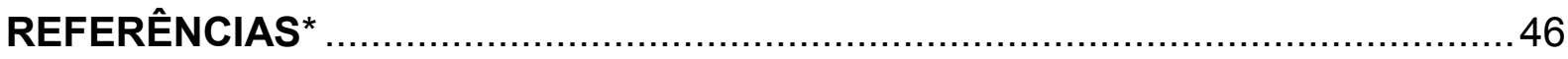




\section{INTRODUÇÃO}

\subsection{MEMÓRIA}

A formação da Memória requere aquisição, formação, conservação e evocação de informações. A aquisição é também chamada de aprendizado ou aprendizagem e a evocação também é chamada de lembrança ou recuperação. Só lembramos aquilo que gravamos, aquilo que foi aprendido (IZQUIERDO, 2011).

Podemos afirmar que somos aquilo que recordamos, literalmente. Não podemos fazer aquilo que não sabemos, nem comunicar nada que desconheçamos, Isto é, nada que não esteja na nossa memória. Também não estão a nossa disposição os conhecimentos inacessíveis, nem formam parte de nós episódios pelos quais esquecemos ou nunca atravessamos. O acervo da nossa memória faz com que cada um de nós seja o que é: um indivíduo, um ser para qual não existe outro idêntico. O conjunto de memórias de cada um, determina aquilo que se denomina personalidade ou forma de ser (IZQUIERDO, 2011).

A capacidade de evocar informações, momentos vividos, imagens da infância, entre outros, confere individualidade às pessoas. Acredita-se que com o envelhecimento ocorra declínio dos processos mentais devido a modificações moleculares, o que pode acarretar significativa alteração da função cognitiva dos indivíduos. Essa perda também pode ser influenciada por fatores psicológicos e/ou emocionais como ansiedade, depressão, estresse e alta exigência pessoal (IZQUIERDO, 2002; SEGOVIA; ARCO; MOTA, 2009; SQUIRE; KANDEL, 2003). Principalmente na velhice, a preservação da memória é um dos fatores primordiais para a manutenção da qualidade de vida.

Supõe-se geralmente que a memória vem em muitas formas e que cada uma envolve um processo neural distinto com alterações biológicas diferentes. Ainda não sabe-se como caracterizar essas formas e a quais sistemas elas estão relacionadas, e quais processos moleculares e celulares que fazem com que a memória persista. Os trabalhos nesse campo de pesquisa, nos últimos anos são para responder essas perguntas (NADEL; HARDT, 2011). 


\section{2 ÀREAS CENTRAIS RELACIONADAS À MEMÓRIA}

As áreas cerebrais que envolvem os processos de memória são: lobos temporais mediais (hipocampo, amígdala e córtex rinal), córtex pré-frontal, cerebelo, septo medial, neurônios, neurotransmissores, entre outras (GAZZANIGA; HEATHERTON, 2005; IZQUIERDO, 2002; LENT, 2004).

Os lobos temporais mediais são responsáveis por coordenar o fortalecimento entre as ligações neurais. O armazenamento de fato está relacionado com os locais específicos de processamento durante a percepção da nova informação sendo, portanto, atrelado às áreas sensoriais (GAZZANIGA; HEATHERTON, 2005).

A comunicação entre os neurônios é feita pelos neurotransmissores, como, acetilcolina, noradrenalina , GABA, serotonina, glutamato e dopamina, que podem enfraquecer ou intensificar os processos de memória (GAZZANIGA; HEATHERTON, 2005; IZQUIERDO, 2002).

Existem substâncias, que também possuem papel importante na facilitação ou prejuízo dos processos de memória, são conhecidas como neuromoduladores. Entre eles podemos citar: a $\beta$-endorfina (de natureza peptídica), a vasopressina e a ocitocina (hormônios hipofisários), o óxido nítrico (NO) e o monóxido de carbono (CO) (IZQUIERDO, 2002). O oxido nítrico atua melhorando o fluxo sanguíneo no cérebro, por exemplo, o que proporciona uma facilitação ou melhora da memória, já a vasopressina por diminuir o fluxo sanguíneo e o monóxido de carbono por diminuir a oxigenação no cérebro promovem um prejuízo nos processos de memória.

Essas substâncias envolvidas na regulação e modulação da memória também estão descritas como reguladoras homeostáticas do exercício (SANTOS.; MILANO; ROSAT, 1998). A partir desta constatação, surge a possibilidade de se identificar uma regulação do efeito do exercício físico na modulação da memória.

\subsection{CLASSIFICAÇÃO DAS MEMÓRIAS}

Há dois tipos de classificações a respeito das memórias, quanto à natureza e ao tempo de duração.

No que diz respeito à natureza das memórias elas podem ser classificadas como: as denominadas memórias declarativas que registram fatos, eventos ou 
conhecimentos e as memórias de procedimento que armazenam capacidades ou habilidades motoras e sensoriais (IZQUIERDO, 2002). Mas segundo Lent (2004), as memórias quanto à sua natureza ainda podem ser classificadas em: memória explícita (declarativa), memória implícita (não-declarativa) e memória operacional.

A memória explícita compreende tudo o que pode ser evocado por meio de palavras, essa memória pode ser subdividida em: memória episódica (eventos datados) e semântica (eventos atemporais). Já a memória implícita, não precisa ser evocada por meio de palavras e possui quatro subdivisões. A primeira é chamada de memória de representação perceptual, que se refere, por exemplo, à imagem de um objeto que é preliminar à compreensão do que ele significa. A segunda subdivisão refere-se à memória de procedimentos, que compreende os hábitos, habilidades, por exemplo, andar de bicicleta e a Memória operacional, também conhecida como memória de trabalho, tem a função de possibilitar a realização de tarefas do dia-adia como discar um número de telefone ou recordar o nome de alguém que encontramos na rua. Além de ser responsável também pela compreensão da linguagem, raciocínio lógico e resolução de problemas e as outras subdivisões conhecidas como associativa e não-associativa, que são quando há ou não a associação de um evento ao condicionamento da memória (LENT, 2004).

Em relação ao tempo de duração das memórias, elas são classificadas em: memória imediata (ultra-rápida), memória de curta duração (MCD) e memória de longa duração (MLD) (IZQUIERDO, 2002; LENT, 2004).

Existem memórias que duram apenas alguns segundos, tempo necessário para que a informação seja processada. Não deixam traços de memória e não produzem arquivos. Poucas alterações bioquímicas acontecem e parecem depender, fundamentalmente, da atividade elétrica dos neurônios do córtex pré-frontal, conhecidas como memória de trabalho ou memória imediata. Essas memórias exercem papel gerenciador, determinam se as novas informações devem ser gravadas ou não e avaliam se as informações transmitidas nas sinapses são recentes ou já existiam. Essas memórias são denominadas de memórias imediatas, ultra-rápidas ou de trabalho (IZQUIERDO, 2002).

O papel da MCD é, basicamente, o de manter o indivíduo em condições de responder através de uma "cópia" da memória principal, enquanto esta ainda não tenha sido formada. Essa memória cumpre o seu papel de "alojamento temporário" 
da memória, enquanto "sua casa" definitiva ainda está sendo construída. Izquierdo (2002) assegura através de experimentos farmacológicos, que a MCD não inclui ativação de fatores de transcrição, expressão de genes ou síntese de proteínas.

Uma série de processos metabólicos no hipocampo e em outras estruturas cerebrais, que duram entre 3 e 8 horas, são responsáveis pela formação da memória de longa duração (IZQUIERDO; MEDINA, 1997). Enquanto estes processos não estiverem sedimentados, as MLD são extremamente suscetíveis a influências internas e externas. O conjunto desses processos e seu resultado final denominam-se consolidação. O processo de consolidação das MLD corresponde a modificações permanentes ou, pelo menos, muito duradouras da memória mantendo a forma e a função das sinapses neurais. (MCGAUGH, 1989; SANTOS; MILANO; ROSAT, 1998).

Fisiologicamente, as memórias de curta e de longa duração assemelham-se no que diz respeito aos conteúdos das informações, compartilham as mesmas informações aferentes e eferentes e os mesmos "input" (mecanismos de análise) e "output" (mecanismos de evocação). Suas diferenças caracterizam-se por não serem parte de um mesmo processo, mas sim de duas séries de processos paralelos e independentes (IZQUIERDO, 2002).

\subsection{SISTEMA COLINÉRGICO E A MEMÓRIA}

O sistema colinérgico possui papel importante na modulação dos processos de aprendizagem e memória. A maioria das inerências colinérgicas parte do prosencéfalo basal, área formada por neurônios localizados nos núcleos: septal medial, banda diagonal, substantia innominata e núcleo basal de Meynert (MCKINNEY; JACKSONVILLE, 2005). Esses neurônios projetam-se para o hipocampo, neocortex, partes do córtex límbico e amígdala e modulam assim, as funções cognitivas.

A acetilcolina ( $\mathrm{ACh}$ ) é o neurotransmissor do sistema colinérgico. A ACh é um neurotransmissor pertencente à classe das aminas, atua na transmissão de funções cognitivas, principalmente na consolidação da memória. É responsável pela neurotransmissão em sítios do sistema nervoso periférico e em várias localizações subcorticais do sistema nervoso central. A ACh é sintetizada pela reação de colina 
com um grupo acetato ativado por uma coenzima, a Acetil Coenzima A, nos botões terminais de neurônios pré-sinápticos. Essa reação é facilitada pela presença da enzima colina-acetil-transferase (ChAT). O neurotransmissor é então estocado em vesículas pré-sinápticas e, quando há a excitação neuronal, o conteúdo vesicular é liberado na fenda sináptica, ativando receptores de neurônios pós-sinápticos. Após a ação do neurotransmissor a enzima acetilcolinesterase, no espaço sináptico, degrada a acetilcolina em colina e acetato. Essa colina liberada é rapidamente recaptada pelo terminal pré-sináptico e reutilizada na síntese de mais neurotransmissor.Com o envelhecimento, observa-se uma diminuição progressiva da densidade da enzima ChAT, levando a uma diminuição da reserva de ACh nos neurônios, especialmente naqueles localizados no córtex frontotemporal e no hipocampo. Essa diminuição do tônus colinérgico também pode ser explicada pela redução da concentração de receptores de ACh nessas regiões (KATZUNG, 2010; RANG; et al, 2008).

Uma estrutura subcortical, rica em neurônios colinérgicos, núcleo basal de Meynert, é responsável por processos de atenção e de consolidação da memória. Recebe aferências do sistema límbico e envia projeções colinérgicas para todo o córtex cerebral, o que explica a ligação, amplamente conhecida, das emoções (sistema límbico) com a fixação da memória. A ação da acetilcolina, com origem no núcleo basal de Meynert, sobre a consolidação da memória, ocorre pela excitação de neurônios corticais, que se tornam mais receptivos a outros impulsos excitatórios, facilitando a fixação preferencial de informações. A degeneração de áreas colinérgicas do sistema nervoso central, como núcleo basal de Meynert, está implicada na fisiopatologia da demência do tipo Alzheimer. A doença de Alzheimer foi caracterizada, inicialmente por um déficit de memória recente e operante, mas acredita-se que a atrofia das aferências colinérgicas corticais seria decorrente da diminuição de fatores tróficos liberados ao redor do terminal sináptico e que são transportados para o corpo neuronal por transporte axonal retrógrado. Com a privação de estímulos, os neurônios colinérgicos entrariam em processo de morte celular (DE MATTOS PIMENTA, 2009).

A relevância do sistema colinérgico para eventos relacionados à memória pode ser observada pelo modesto benefício obtido pelo uso de drogas inibidoras da acetilcolinesterase em pacientes demenciados. Apesar disso, cabe ressaltar o 
caráter sintomático da relativa melhora que muitas vezes, nada mais é do que uma lentidão na velocidade de perdas cognitivas. Recentemente, resultados têm sugerido que haveria um continuum na patologia de vias colinérgicas que ligaria o envelhecimento normal ao declínio cognitivo leve e à demência do tipo Alzheimer (MESULAM et al., 2004).

Muitos trabalhos sugerem que as perdas neuronais relacionadas tanto com o envelhecimento normal, quanto com demências progressivas, como a Doença de Alzheimer, correspondem à perda de neurônios colinérgicos no prosencéfalo basal, assim como uma redução significativa na atividade da enzima ChAT (GAUTHIER, 2002). Esses achados subsidiam a "hipótese colinérgica" para a Doença de Alzheimer e justificam a utilização de fármacos anticolinesterásicos no tratamento dos seus sintomas (HAKE; FARLOW, 2001; HOGAN; PATTERSON, 2002).

As vias colinérgicas no sistema nervoso central têm seus efeitos mediados por duas classes de receptores: os receptores metabotrópicos muscarínicos e os receptores ionotrópicos nicotínicos.

Os receptores nicotínicos (nAChRs) fazem parte da super-família de receptores associados ao canal iônico e que inclui os receptores de glicina, ácido gama aminobutírico $\left(G A B A_{A}\right)$, glutamato (AMPA e NMDA) e a maioria dos receptores de serotonina. Os nAChRs são encontrados nos músculos esqueléticos (receptores musculares), nos gânglios autonômicos e em muitas áreas cerebrais (receptores neuronais). A principal propriedade farmacológica desses receptores é a capacidade de transformar um sinal químico, produzido pela ligação da ACh com seu sítio de reconhecimento, em uma mudança conformacional do complexo receptor-canal iônico, permitindo o fluxo de íons e desencadeando a contração muscular e a transmissão neuro-neural. São, portanto, proteínas essenciais para a transmissão sináptica (ARIAS, 1997; CLEMENTI; FORNASARI; GOTTI, 2000).

Atualmente, em vertebrados, foram identificadas 17 subunidades para os receptores nicotínicos neuronais ( $\alpha 1-\alpha 10, \beta 1-\beta 4, \gamma, \delta$ e $\varepsilon$ ) (BOCCIA et al., 2010; BUCKINGHAM et al., 2009). Essas subunidades se combinam para formar receptores homopentaméricos ou heteropentaméricos que possuem características eletrofisiológicas e neuroquímicas singulares (NASHMI; LESTER, 2006).

Os receptores formados pelas subunidades $\alpha 4-\beta 2$ e $\alpha 7$ são os encontrados com maior frequência no sistema nervoso central (WEVERS; SCHRÖDER, 1999). 
Aparentemente, esses receptores possuem uma função moduladora nas transmissões sinápticas, função essa que se evidencia pela variada distribuição e localização dos mesmos. Os receptores localizados em regiões pré-sinápticas e perisinápticas aumentam a liberação de neurotransmissores. Enquanto que, aqueles localizados em regiões pós-sinápticas contribuem com transmissões excitatórias rápidas. Os outros receptores que se localizam em regiões não-sinápticas modulam vários sistemas de neurotransmissores, influenciando sua excitabilidade neuronal (DANI; BERTRAND, 2007; MCGEHEE; ROLE, 1996; ROLE; BERG, 1996).

\subsection{ATIVIDADE FÍSICA}

A prática de atividade física parece estar "introjetada" no pensamento contemporâneo, haja vista seu apelo estético. Sobretudo, a importância atrelada à promoção da saúde vem sendo cada vez mais difundida, principalmente através dos profissionais da saúde.

Todavia, essa divulgação ainda não atingiu os indivíduos de uma maneira eficaz, visto que a concretização do exercício físico ainda é hábito de poucos. Freqüentemente, ouvimos dizer que atividade física e boa alimentação são as "chaves mestras" no bom funcionamento do organismo humano, mas elas devem ser exploradas e bem orientadas. Não é qualquer tipo de exercício físico que é benéfico, ou seja, deve ser adequado quanto à intensidade, à freqüência e à duração, além de considerar a faixa etária e as morbidades já instaladas para ser estabelecida uma rotina de práticas.(SANTOS; MILANO; ROSAT, 1998)

Estudos epidemiológicos contemporâneos vêm demonstrando expressiva associação entre estilo de vida ativo, menor possibilidade de morte e melhor qualidade de vida. Considerando a alta prevalência das doenças crônicodegenerativas, aliada ao risco relativo do sedentarismo, a implementação de políticas públicas que favoreçam e estimulem a prática regular de atividade física, caracteriza-se como eficiente agente de saúde pública, com significativo impacto na redução dos custos com tratamentos (CARVALHO et al., 1996).

A Organização Mundial da Saúde (OMS) publicou um documento intitulado: Estratégia Global para Alimentação, Atividade Física e Saúde (EG/OMS, 2004), o qual recomenda que “(...) os indivíduos adotem níveis adequados de atividade física 
durante toda a vida. Diferentes tipos e quantidades de atividade física são necessários para obter diferentes resultados na saúde: a prática regular de 30 minutos de atividade física de moderada intensidade, na maior parte dos dias, reduz o risco de doenças cardiovasculares e câncer de cólon e de mama. O treinamento de resistência muscular e equilíbrio podem reduzir quedas e aumentar a capacidade funcional nos idosos. Maiores níveis de atividade física podem ser necessários para o controle de peso".

É nesse âmbito que a atividade física ocupa um importante papel na promoção da saúde, sendo, portanto, um alvo interessante para as políticas públicas. Existe evidente diferença entre "atividade física" e "exercício físico".

A atividade física pode ser definida como qualquer movimento corporal, produzido pela musculatura esquelética, que despende uma quantidade energética maior do que os níveis de repouso. Já o exercício físico (um de seus principais componentes) é uma atividade planejada, sistematizada, estruturada e repetitiva que apresenta como objetivos finais ou intermediários o aumento ou a manutenção da saúde e da aptidão física (ANTUNES et al., 2004).

O exercício físico consiste em um excelente modelo de resposta integrada de múltiplos sistemas corporais. No organismo, manifesta-se através das respostas metabólicas, ventilatórias, cardiovasculares, entre outras (SILVERTHORN, 2003).

De acordo com McAuley e Rudolph (1995), o exercício contribui para a integridade cardiovascular, aumenta o transporte de oxigênio para o cérebro, auxilia a síntese e degradação de neurotransmissores e, ainda, atua na diminuição da pressão arterial, dos níveis de colesterol e triglicérides, na inibição da agregação plaquetária, no aumento da capacidade funcional e na melhora da qualidade de vida.

Além disso, o exercício crônico aumenta a expressão das "heat shock proteins" (HSPs), proteínas de estresse com a função de reparo e prevenção de danos teciduais no músculo esquelético e cardíaco (VANCINI et al., 2005) por exemplo, sendo capaz de reduzir a extensão da apoptose (morte celular programada) em ratos que realizaram exercício aeróbio moderado, por diminuir os níveis de genes pró-apoptóticos e aumentar os níveis dos genes anti-apoptóticos, como observado ao final do treinamento (SIU et al., 2004). 


\subsection{EXERCÍCIO FÍSICO COMO FATOR DE PROTEÇÃO AOS DÉFICITS COGNITIVOS}

O exercício físico é considerado um agente estressor, visto que exige do organismo adaptações fisiológicas, interferindo na sua homeostase. A variabilidade das respostas endócrinas e metabólicas depende do tipo, da intensidade e da duração do exercício, do estado de condicionamento e das características físicas do indivíduo. Dessa forma, os mecanismos hormonais e neuro-hormonais que influenciam a memória e os mecanismos envolvidos no exercício físico, conduzem a especulações a respeito da possível influência do exercício na memória (SANTOS; MILANO; ROSAT, 1998).

Uma informação adquirida pode ser melhor evocada se houver similaridade em relação ao contexto neuro-humoral do momento da aquisição, sendo que não é necessária uma liberação simétrica dos hormônios em ambas as fases do processo mnemônico. Isso representa o conceito de "dependência de estado" (SANTOS et al., 1998).

Santos et al. (1998) inferem que "(...) para que seja criada uma "dependência de estado" favorável à evocação da memória através do exercício físico, este deverá ser de alta intensidade (acima de $70 \%$ do $\mathrm{VO}_{2}$ - volume de oxigênio - máximo) ou então, de intensidade moderada e longa duração (acima de 50 minutos) de modo que haja uma liberação significativa das substâncias: catecolaminas, vasopressina, ACTH, $\beta$-endorfina e, também, interação necessária entre o sistema opióide, adrenérgico e noradrenérgico". Alertam ainda que os exercícios intensos ou de intensidade moderada, porém de longa duração, seriam os de maior probabilidade de criação desta dependência de estado, e, conseqüentemente, melhor relacionam o exercício físico à facilitação da evocação da memória.

O exercício físico é acompanhado por inúmeras mudanças bioquímicas e fisiológicas, dependendo do seu tipo e da sua intensidade, duração e freqüência. Em literatura já estão bem esclarecidas as respostas e adaptações ao exercício das catecolaminas, vasopressina, ACTH e do opióide $\beta$-endorfina. Entretanto, ainda não se conhecem quais as concentrações plasmáticas hormonais atingidas em resposta ao estresse do exercício físico que são necessárias para influenciar de maneira significativa a modulação da memória (SANTOS; MILANO; ROSAT, 1998). 


\subsection{O DESTREINAMENTO FÍSICO}

Embora um pico aumentado de $\mathrm{VO}_{2}$ e a bradicardia de repouso estejam relacionados com um melhor desempenho físico e melhor funcionamento cardiovascular, essas respostas são gradualmente perdidas quando o treinamento é descontinuado. Um declínio significativo na função cardiovascular e no potencial metabólico muscular ocorre em dias ou semanas após o destreinamento. Esse declínio está associado com uma redução significativa no pico de $\mathrm{VO}_{2}$ (MUJIKA; PADILLA, 2001).

Os mecanismos envolvidos na melhora do desempenho físico e função cardiovascular foram amplamente estudados (CARTER; BANISTER; BLABER,. 2003; DE ANGELIS et al., 2004). Por outro lado, pouco se sabe sobre os mecanismos fisiológicos responsáveis pelo destreinamento físico. Uma associação entre uma redução do pico de $\mathrm{VO}_{2}$ e alterações no comprimento de miócitos após quatro semanas de destreinamento foi demonstrada em ratos (KEMI et al., 2004). Além disso, a perda da bradicardia de repouso também foi observada após duas semanas de destreinamento (EVANGELISTA et al., 2005), mostrando que apenas duas semanas de sedentarismo são necessárias para a perda dos benefícios cardiovasculares adquiridas com o treinamento físico.

Da mesma forma, pouco se sabe sobre os efeitos do destreinamento físico sobre a manutenção da memória e funcionamento do sistema colinérgico central de roedores.

Uma melhor resposta à exposição à tarefa de esquiva inibitória foi demonstrada em ratos treinados por oito semanas sem ter sido evidenciado, entretanto, a manutenção do padrão comportamental nos animais ou o nível das neurotrofinas BDNF e NGF após o destreinamento por mais oito semanas (RADAK et al., 2006). Em humanos, após 8 semanas de treinamento físico, o destreinamento por 4 semanas reduziu a atenção em funções executivas (HANSEN et al., 2004). Um detalhe importante é que em ambos os trabalho, os grupos foram avaliados com relação às funções cognitivas após o início dos treinamentos. Portanto, a manutenção da memória de uma tarefa adquirida quando os indivíduos eram sedentários não foi avaliada. 
Em nosso grupo de pesquisa, utilizando o treinamento físico moderado em esteira ergométrica após a submissão dos animais a uma tarefa cognitiva, verificamos uma melhora de $126 \%$ na memória de ratos com baixo nível de retenção de informações, bem como um aumento da densidade de receptores colinérgicos nicotínicos alfa7 em células piramidais do hipocampo e no núcleo accumbens (ALBUQUERQUE et al., submetido). Os efeitos do treinamento físico, de alta intensidade, bem como do destreinamento físico foram avaliados neste trabalho. 


\section{OBJETIVOS}

Avaliar os efeitos do treinamento de alta intensidade e do destreinamento físico sobre a manutenção da memória de longa duração de camundongos fêmeas C57BI/6.

Avaliar a densidade do receptor nicotínico alfa7 em hipocampo, nos diferentes grupos.

Avaliar a densidade da neurotrofina BDNF na mesma área cerebral, nos diferentes grupos. 


\section{MATERIAL E MÉTODOS}

\subsection{ANIMAIS}

Foram utilizados 32 camundongos fêmeas C57BI/6, de 3 a 5 meses de idade, que foram mantidos no Biotério da Escola de Artes, Ciências e Humanidades da Universidade de São Paulo, com acesso à água e comida ad libitum. Os animais são provenientes do biotério do Departamento de Ciências Fisiológicas da Faculdade de Ciências Médicas da Santa Casa de São Paulo.

Todos os procedimentos experimentais foram realizados de acordo com os "princípios éticos para uso de animais de laboratório" descritos pela Sociedade Brasileira em Ciência de Animais de Laboratório (SBCAL, antigo Colégio Brasileiro de Experimentação Animal, COBEA) e de acordo com a Lei Arouca, aprovada em 2008. O projeto foi aprovado pelo Comitê de Ética em Uso de Animais da Escola de Artes, Ciências e Humanidades da Universidade de São Paulo (CEUA-EACH-USP), sob protocolo número 001/2013.

\subsection{AVALIAÇÃO DA MEMÓRIA DE LONGA DURAÇÃO}

Para avaliar a memória de longa duração, foi utilizado o equipamento de esquiva inibitória, o qual possui dois compartimentos, um escuro e outro claro (este com uma lâmpada fixada na porção superior), intercomunicados por uma passagem na parede divisória. O chão é formado por barras metálicas, que permitem a passagem de uma corrente elétrica com intensidade controlável. $\mathrm{Na}$ sessão de aquisição, o animal foi colocado no lado claro da caixa e teve o tempo máximo de 300 segundos para explorar o local. Se ele passasse para o lado escuro, a porta se fechava automaticamente e ele recebia um leve choque nas patas $(0,5 \mathrm{~mA})$ por dois segundos. A latência do animal para atravessar de um lado para o outro da caixa foi registrada.

As avaliações de evocação da memória (Sessão Teste - ST)foram realizadas 24 horas após a sessão de aquisição (SA), após quatro semanas de treinamento físico (Reteste I) e novamente após duas semanas (Reteste II) onde os animais do 
grupo experimental foram divididos em dois outros grupos, "treinados" e "destreinados", de acordo com o desenho experimental abaixo.

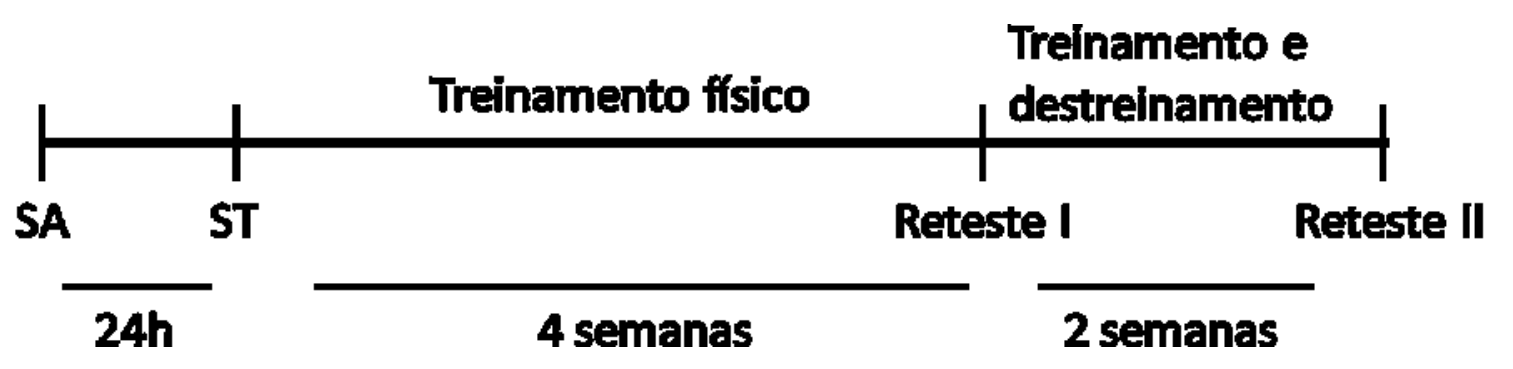

O teste de memória em esquiva inibitória tem base no princípio de que quanto mais tempo o animal permanece no lado claro da caixa, maior será sua lembrança com relação ao contexto.

\subsection{AVALIAÇÃO DA ATIVIDADE LOCOMOTORA}

A fim de assegurarmos que as respostas observadas no teste de esquiva inibitória não decorreram de alterações da atividade motora, todos os animais foram submetidos a um teste de atividade locomotora adaptado de Viel et al., 2008. O equipamento (modelo Ugo Basile, Italy) consiste de uma caixa de acrílico transparente $(35 \mathrm{~cm} \times 23 \mathrm{~cm} \times 20 \mathrm{~cm}$ ) cuja base foi dividida em quadrados de $8 \mathrm{~cm} \times$ $8 \mathrm{~cm}$. Cada animal foi colocado individualmente na caixa e a deambulação e exploração vertical foram observadas por cinco minutos.

\subsection{PROTOCOLO DE TREINAMENTO FÍSICO E DESTREINAMETO}

O treinamento físico dos camundongos em piscina foi realizado como descrito por Evangelista et al. (2003). O sistema consiste de dois tanques de vidro de dimensões diferentes. O tanque externo possui 100 de largura, $60 \mathrm{~cm}$ de comprimento e $50 \mathrm{~cm}$ de altura. O tanque interno foi dividido em 10 espaços com área de $15 \times 15 \mathrm{~cm}$ e profundidade de $35 \mathrm{~cm}$, permitindo o treinamento individual. Para prevenir que os animais boiassem durante as sessões de treinamento, bolhas foram produzidas por tubos conectados a um sistema de bombeamento de ar. Um 
sistema de aquecimento manteve a temperatura da água entre 30 e $32^{\circ} \mathrm{C}$. Um filtro de água com capacidade de $420 \mathrm{l} / \mathrm{h}$ foi usado para manter o sistema limpo (Figura 1).

Figura 1 - Piscina de Treinamento.
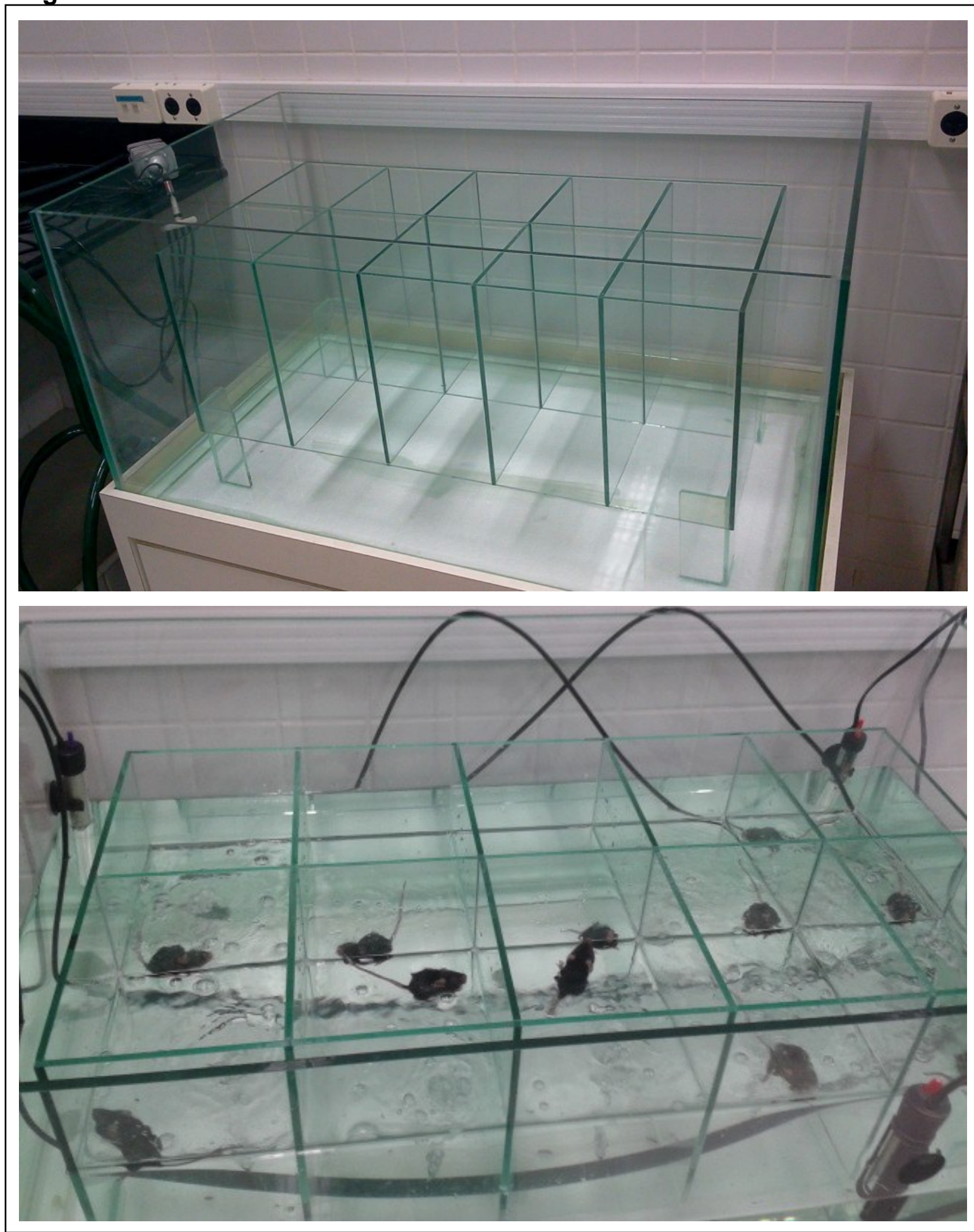

Foto do treinamento na piscina adaptada para camundongos do Biotério do Laboratório de Biomedicina e Biotecnologia da Escola de Artes, Ciências e Humanidades/Universidade de São Paulo. 
Após as observações comportamentais, os animais foram divididos em dois grupos: Controle (Sedentários) e Experimental (Treinados).

O grupo Controle permaneceu nas caixas sendo apenas submetido a 5 minutos de natação, 3 vezes por semana. $O$ grupo Experimental foi submetido a dois treinos por dia, com aumento progressivo diário do tempo de natação até atingir 90 minutos, com intervalo de 4 horas entre os treinos, 5 vezes por semana, durante 4 semanas, que assemelha-se ao treinamento de atletas de alta performance. Após esse período, uma nova avaliação comportamental foi realizada. Em seguida, o grupo Experimental foi dividido em dois: Experimental Treinado (que continuou o protocolo de treinamento físico por mais 2 semanas) e Experimental Destreinado (que passou a ser submetido à mesma exposição do grupo controle, por mais duas semanas).

\subsection{AVALIAÇÃO DE PESO CORPORAL E CONSUMO DE ÁGUA E COMIDA}

O peso corporal dos animais foi avaliado semanalmente durante o tempo de treinamento e o tempo de observação.

O consumo de água e de ração também foi monitorado semanalmente pesando-se a ração e medindo o volume de água da garrafa das caixas dos animais.

\subsection{RETIRADA DOS CÉREBROS}

Após os treinamentos e ensaios comportamentais, os animais foram mortos por decapitação e tiveram seus cérebros retirados. As amostras foram imediatamente congeladas em dimetilbutano em gelo-seco $\left(-45^{\circ} \mathrm{C},-55^{\circ} \mathrm{C}\right)$ e armazenadas a $-80^{\circ} \mathrm{C}$ até o uso. A preservação das amostras por congelamento e não por fixação química permite a utilização em diferentes tipos de análises (radioautografia, western-blot, imunohistoquímica). 


\subsection{DETERMINAÇÃO DA DENSIDADE DO RECEPTOR ALFA 7, EM HIPOCAMPO PELO MÉTODO DE WESTERN-BLOTTING}

O Hipocampo foi separado e homogeneizado (por sonicação) em tampão de lise contendo $50 \mathrm{mM}$ de Tris- $\mathrm{HCl}(\mathrm{pH} \mathrm{7,4),} \mathrm{0,1 \%} \mathrm{Triton} \mathrm{X-100,} 4$ mM EGTA, $10 \mathrm{mM}$ EDTA e um comprimido de coquetel de inibidores de proteases. Os homogenatos foram centrifugados a $12.000 \mathrm{rpm}$, por $15 \mathrm{~min}$, a $4{ }^{\circ} \mathrm{C}$. A partir do sobrenadante foi feita a dosagem da concentração de proteínas, em cada fração, utilizando-se o método de Bradford (1976), em sistema de leitura de microplacas . Quantidades equivalentes de proteínas foram separadas por gel de poliacrilamida (SDS-PAGE a $10 \%$ ) a $25 \mathrm{~mA}$ por aproximadamente $1 \mathrm{~h}$. Após a corrida eletroforética, as proteínas foram transferidas para uma membrana de nitrocelulose em tampão Tris $25 \mathrm{mM} \mathrm{pH}$ 8,3, glicina $92 \mathrm{mM}$ e SDS $0,1 \%$, a $350 \mathrm{~mA}$ por $2 \mathrm{~h}$ a $4{ }^{\circ} \mathrm{C}$. Terminada a transferência das proteínas, a membrana foi incubada com tampão fosfato contendo Tween-20 $0,1 \%$ e leite desnatado $5 \%$ (Tampão de bloqueio) por $1 \mathrm{~h}$ à temperatura ambiente, sob agitação constante, para o bloqueio das reações não específicas do anticorpo primário. Após lavagem, o material foi incubado com o anticorpo primário anti-alfa 7 (diluído 1:750) ou $\beta$-tubulina (diluído 1:4000) por $16 \mathrm{~h}$ a $4{ }^{\circ} \mathrm{C}$. Em seguida, as membranas foram lavadas conforme descrito anteriormente e incubadas com o anticorpo secundário anti-lgG conjugado com peroxidase de raiz forte (HRP, de HorseRadish Peroxidase) e diluído 1:5000 em tampão de bloqueio por 1 hora à temperatura ambiente. As marcações foram detectadas por quimioluminescência, a emissão de luz foi detectada em autoradiografias.

\subsection{DETERMINAÇÃO DA DENSIDADE DA NEUROTROFINA BDNF EM HIPOCAMPO}

Foi utilizado o método de ELISA (ensaio de imunoabsorção enzimática) para determinar densidade de BDNF nas amostras de hipocampo dos camundongos. Em um tubo Falcon, foram adicionados $10 \mu \mathrm{l}$ do anticorpo Anti-BDNF, em 9,99 $\mathrm{ml}$ de tampão de carbonato (0.025 M bicarbonato e 0,025 M carbonato, $\mathrm{Ph} 9,7)$ para preparar reagente suficiente para os 96 poços da placa de ELISA. Foram colocados $100 \mu \mathrm{l}$ do reagente em cada poço da placa. A placa então foi selada e ficou incubando por aproximadamente $16 \mathrm{~h}$ a $4{ }^{\circ} \mathrm{C}$. 
No dia seguinte, foram feitas três lavagens de cada poço com o tampão TBST(Tris-HCl $20 \mathrm{mM}, \mathrm{NaOH} 150 \mathrm{mM}$ e 0,05\% de Tween 20) e foi então adicionado $200 \mu \mathrm{l}$ do Tampão de bloqueio de amostra 1x(Fornecido pelo kit), em cada poço e ficou incubando por $1 \mathrm{~h}$ em temperatura ambiente. Novamente a placa foi lavada com o tampão TBST por 3 vezes e então uma curva padrão de BDNF foi feita nos primeiros 16 poços da placa, com a concentrações variando entre 0 a 500 $\mathrm{pg} / \mathrm{ml}$.

Em outro tubo Falcon foi adicionado $20 \mu \mathrm{l}$ do anticorpo de BDNF humano a $9.98 \mathrm{ml}$ do Tampão de amostra e bloqueio 1x (diluição 1:500). Foram adicionados então $100 \mu \mathrm{l}$ do anticorpo diluído em cada poço, e então a placa foi selada novamente e incubada por $2 \mathrm{~h}$ em temperatura ambiente com auxílio de um agitador, a seguir a placa foi lavada 5 vezes com TBST e então foi adicionado $100 \mu$ do Anti IgY HRP conjugado (diluição 1:200 em tampão de amostra e bloqueio 1x) em cada poço e permaneceu incubado por $1 \mathrm{~h}$ em temperatura ambiente com auxílio de um agitador (400 \pm 100 rpm), em seguida a placa foi novamente lavada 5x com TBST. Foi então adicionado $100 \mu \mathrm{l}$ em temperatura ambiente de TMB (Tampão de coloração) em cada poço e incubado por 10 minutos, a reação foi interrompida adicionando 100 $\mu l$ de ácido hidroclorídrico $(1 \mathrm{~N})$ em cada poço e foi medida a absorbância a $450 \mathrm{~nm}$ em um leitor de placa por 30 minutos.

\subsection{ANÁLISE ESTATÍSTICA}

Os resultados foram analisados utilizando o programa GraphPad Prism (GraphPad Software, San Diego, CA, versão, 5.0) e as diferenças entre os grupos foram consideradas significativas quando $\mathrm{P}<0,05$.

Os dados obtidos no teste de esquiva inibitória foram expressos como medianas e intervalos interquartis e analisados inicialmente (Sessão de Aquisição X Sessão Teste) pelo teste de Mann Whitney para dados pareados e não paramétricos. Com a inclusão dos Restestes I e II, os dados foram analisados por ANOVA de uma via para dados pareados e não paramétricos (Teste de Friedman) seguido pelo teste de Dunn. 
Os dados obtidos na avaliação da atividade locomotora foram expressos como médias \pm erro-padrão e analisados por análise de variância seguida pelo teste de Tukey-Kramer.

Para análise do peso corporal e do consumo de ração e água foi utilizada a análise de variância de duas vias seguida do teste de Bonferroni, considerando como fatores os grupos experimentais e o tempo.

Para análise da densidade do receptor alfa 7 e a neurotrofina BDNF, foi utilizada a análise de ANOVA de uma via, para dados não-pareados, seguido pelo teste de múltipla comparação de Tukey`s. 


\section{RESULTADOS}

\subsection{AVALIAÇÃO DA ATIVIDADE LOCOMOTORA}

A atividade motora foi registrada em caixa de acrílico por cinco minutos, registrando-se a deambulação e a exploração vertical dos animais.

Os parâmetros foram analisados ao final do período de treinamento. Não houve diferença estatística na deambulação ou exploração vertical dos animais, independente do protocolo experimental a que foram submetidos (Figura 2 A e B).

Figura 2 - Deambulação e exploração vertical

A)

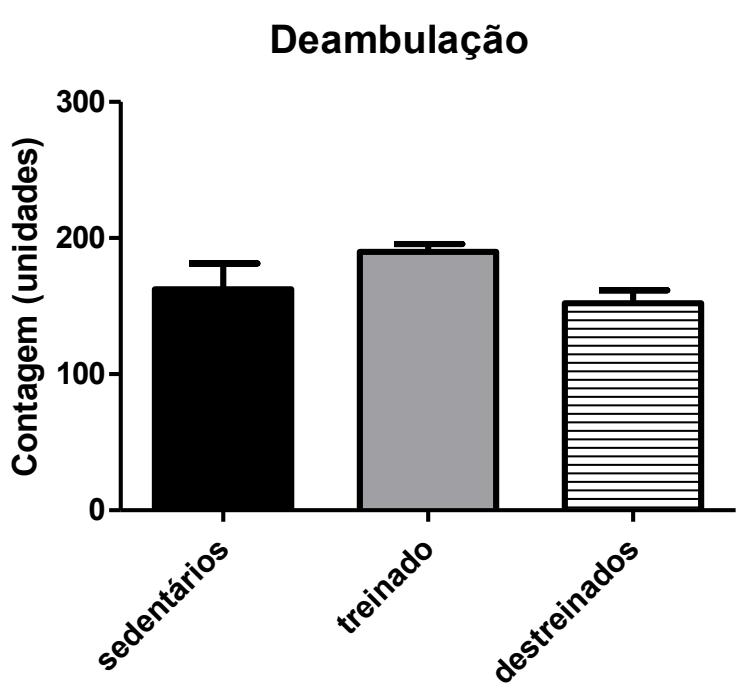

B)

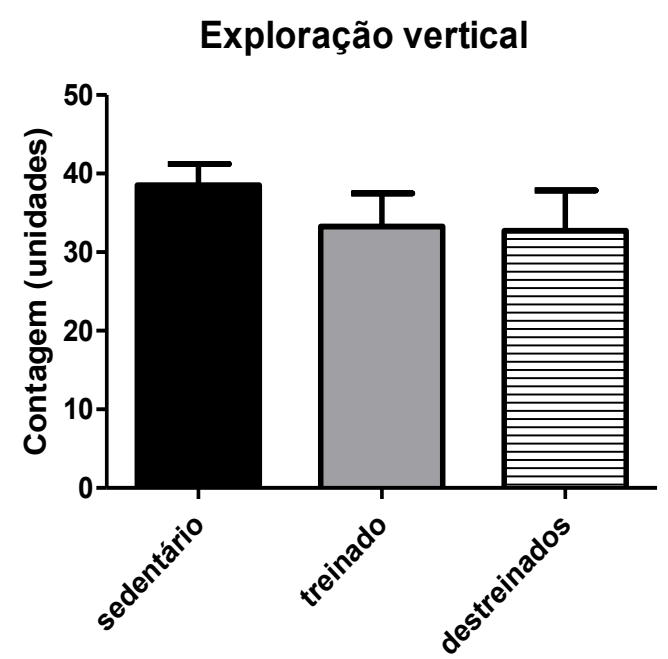

Análise da deambulação e da exploração vertical de camundongos fêmeas submetidos aos diferentes protocolos experimentais. Os dados estão expressos como médias \pm erro-padrão das médias. 


\subsection{AVALIAÇÃO DO PESO CORPORAL}

O peso corporal dos animais foi avaliado semanalmente. Foi verificado que todos os animais apresentaram ganho ponderal significativo ao longo do tempo de observação $\left[F_{(5,85)}=22,62, P<0,0001\right]$ sem, entretanto, haver diferença com relação ao protocolo experimental a que foram submetidos (Figura 3).

Figura 3 - Ganho ponderal

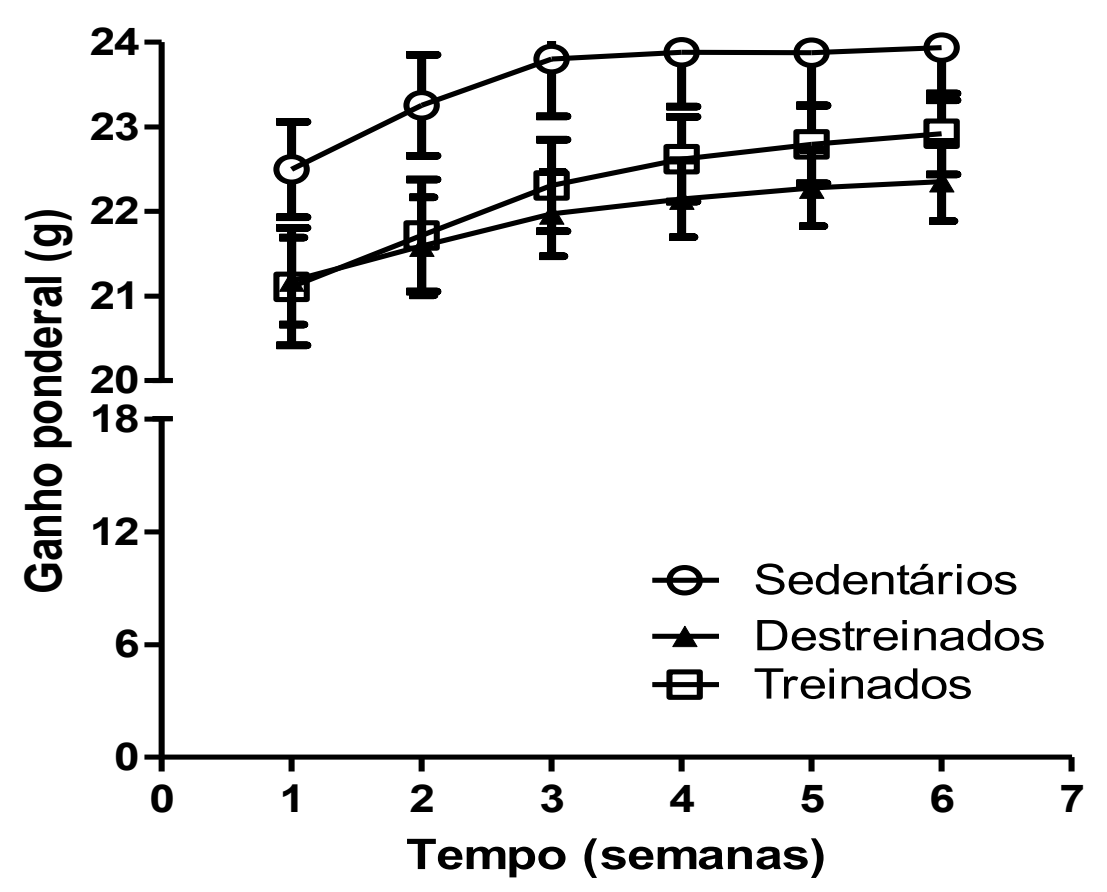

Ganho ponderal de camundongos fêmeas ao longo de 6 semanas de protocolo experimental. 


\subsection{AVALIAÇÃO DO CONSUMO DE RAÇÃO E ÁGUA}

O consumo de água e ração foi avaliado semanalmente ao longo do período de observação. Não houve alteração do consumo de ração e água, como observado na figura 4 .

Figura 4 - Consumo de ração e água.

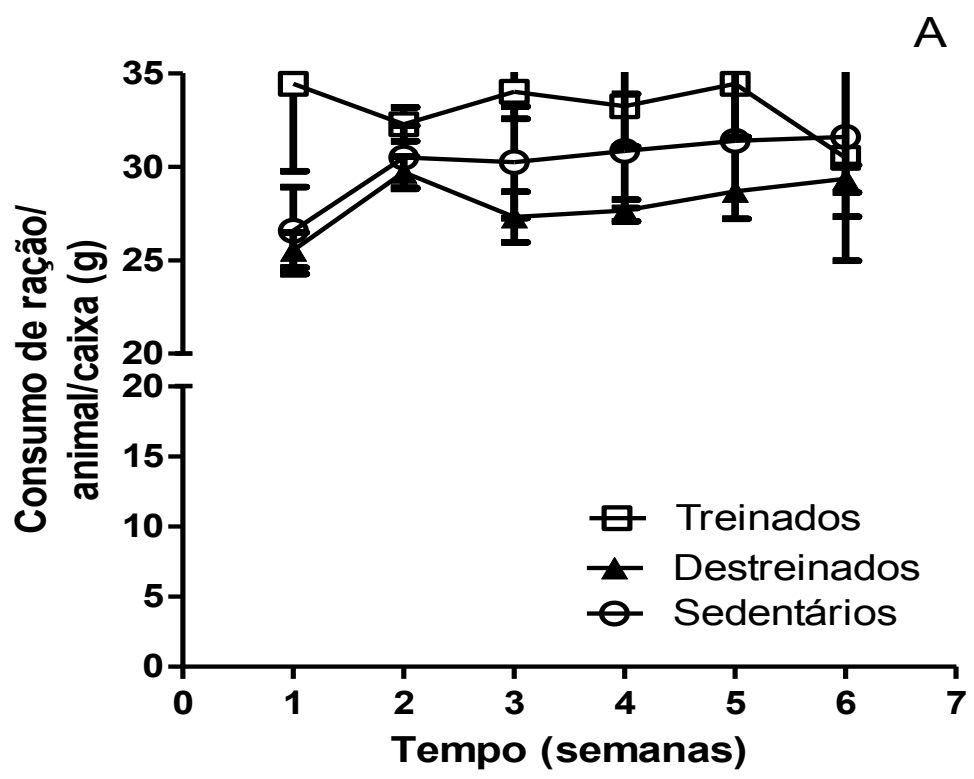

$\mathrm{B}$

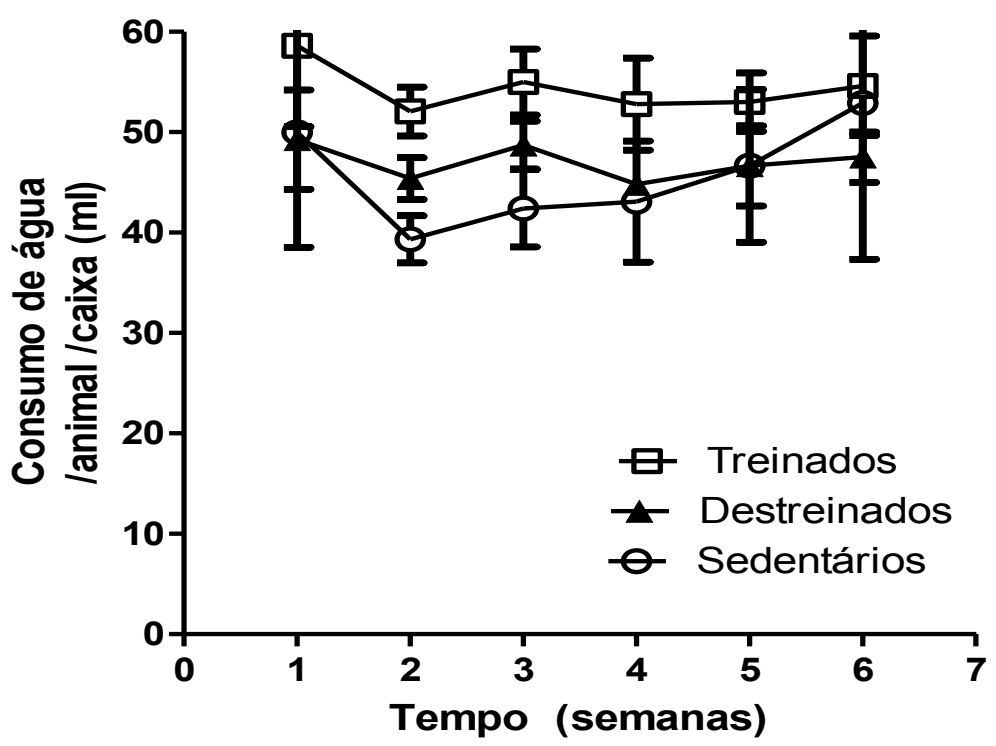

Consumo de ração $(A)$ e água $(B)$ dos camundongos fêmeas ao longo do tempo de observação comportamental. 


\subsection{AVALIAÇÃO DA MEMÓRIA DE LONGA DURAÇÃO}

As avaliações iniciais da evocação da memória (Sessão Teste) foram realizadas 24 horas após a Sessão de Aquisição (SA). Foi observado que os animais apresentaram memória do estímulo, uma vez que a latência para entrada no compartimento escuro da caixa [300 s(113,1 s/ $300 \mathrm{~s})]$ foi significativamente maior ( $P$ $<0,05)$ do que a latência observada na SA [36,6 s (14,5 s / 42,2 s)] (Figura 5).

Após os testes iniciais os animais foram divididos em "sedentários" e "treinados", conforme descrito em "Métodos". Após 4 semanas de treinamento de natação, foi realizado o Reteste I para avaliação da retenção da informação adquirida antes do início do treinamento. O mesmo foi feito com os animais do grupo sedentário. Como pode ser verificado na Figura 6A, os animais do grupo sedentário apresentaram latência significativamente menor no Reteste I [130 s (100,3 s /143,2 s), $\mathrm{P}<0,05]$ do que o observado na sessão de teste (ST-24 h). Os animais treinados por 4 semanas apresentaram diferença significativa entre Reteste I e ST-24h na evocação da memória (Figura 6B e 6C), sugerindo que o treinamento aumentou a evocação da memória do teste.

Após o Reteste I, os animais treinados foram divididos em dois grupos, treinados e destreinados e após duas semanas, todos os animais passaram pela última reavaliação da memória, o Reteste II. Os animais sedentários apresentaram uma pequena melhora, não significativa, da memória anterior (Figura 6A). Por outro lado, os animais treinados (Figura 6B) e os destreinados (Figura 6C) permaneceram com a mesma memória apresentada anteriormente. 
Figura 5 - Avaliação da memória.

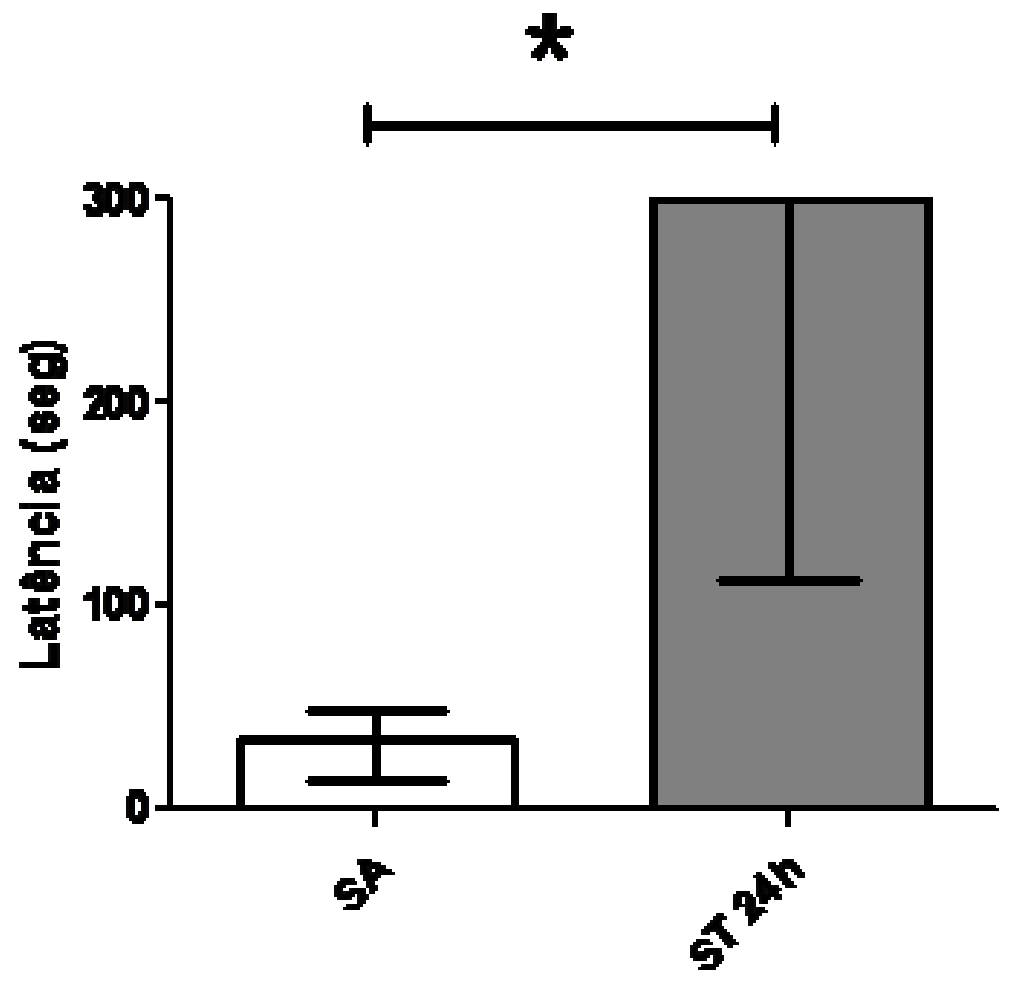

Avaliação da memória em equipamento de esquiva inibitória. Os dados estão expressos como medianas e intervalos interquartis. *: $\mathrm{P}<0,0001$. 
Figura 6 - Evocação da memória.
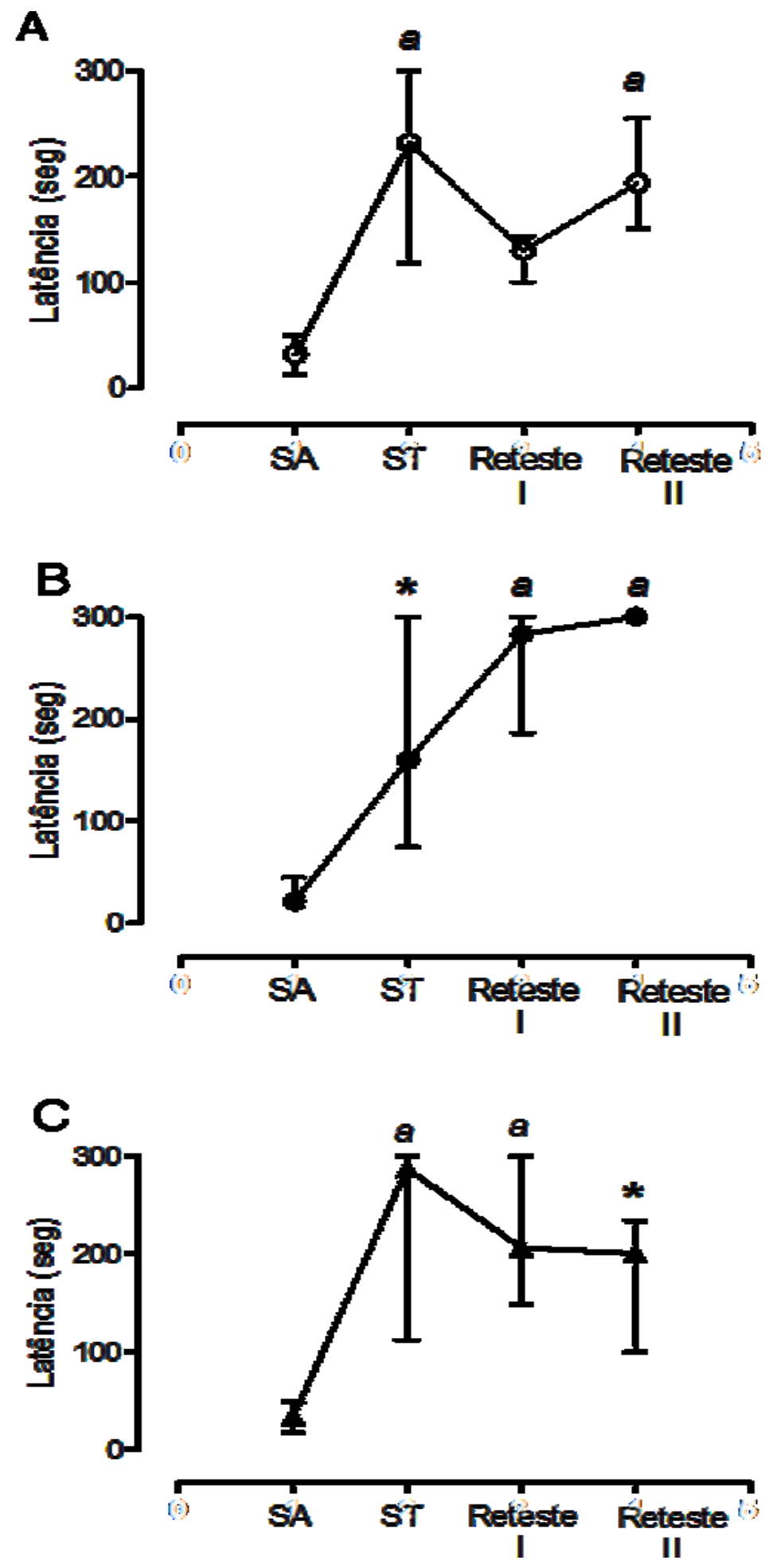

Aprendizagem (sessão de aquisição - SA) e evocação da memória avaliadas em equipamento de esquiva inibitória, 24 horas após SA (ST 24h), quatro semanas após ST-24h (Reteste I) e duas semanas após Reteste I (Reteste II). Os testes foram realizados nos grupos de animais sedentários $(A)$, animais treinados $(B)$ e animais destreinados (C). *: $P<0,01 ; a: P<0,001$ 
Após o Reteste II, os três grupos foram comparados e foi observada uma melhora significativa, da memória dos treinados ( Latência $=300 \mathrm{~s}(300 / 300 \mathrm{~s} \mathrm{P}<$ $0,001)$ quando comparados com os sedentários (Latência $=193,7 \mathrm{~s}(151,1 / 254,9 \mathrm{~s})$. Porém, essa melhora não foi mantida nos animais destreinados, uma vez que estes apresentaram redução significativa (Latência $=200,0 \mathrm{~s}(100,2 / 234,1 \mathrm{~s}, \mathrm{P}<0,001) \mathrm{da}$ memória quando comparados com os animais treinados, equiparando-se aos animais sedentários.

Figura 7 - Comparação da Memória.

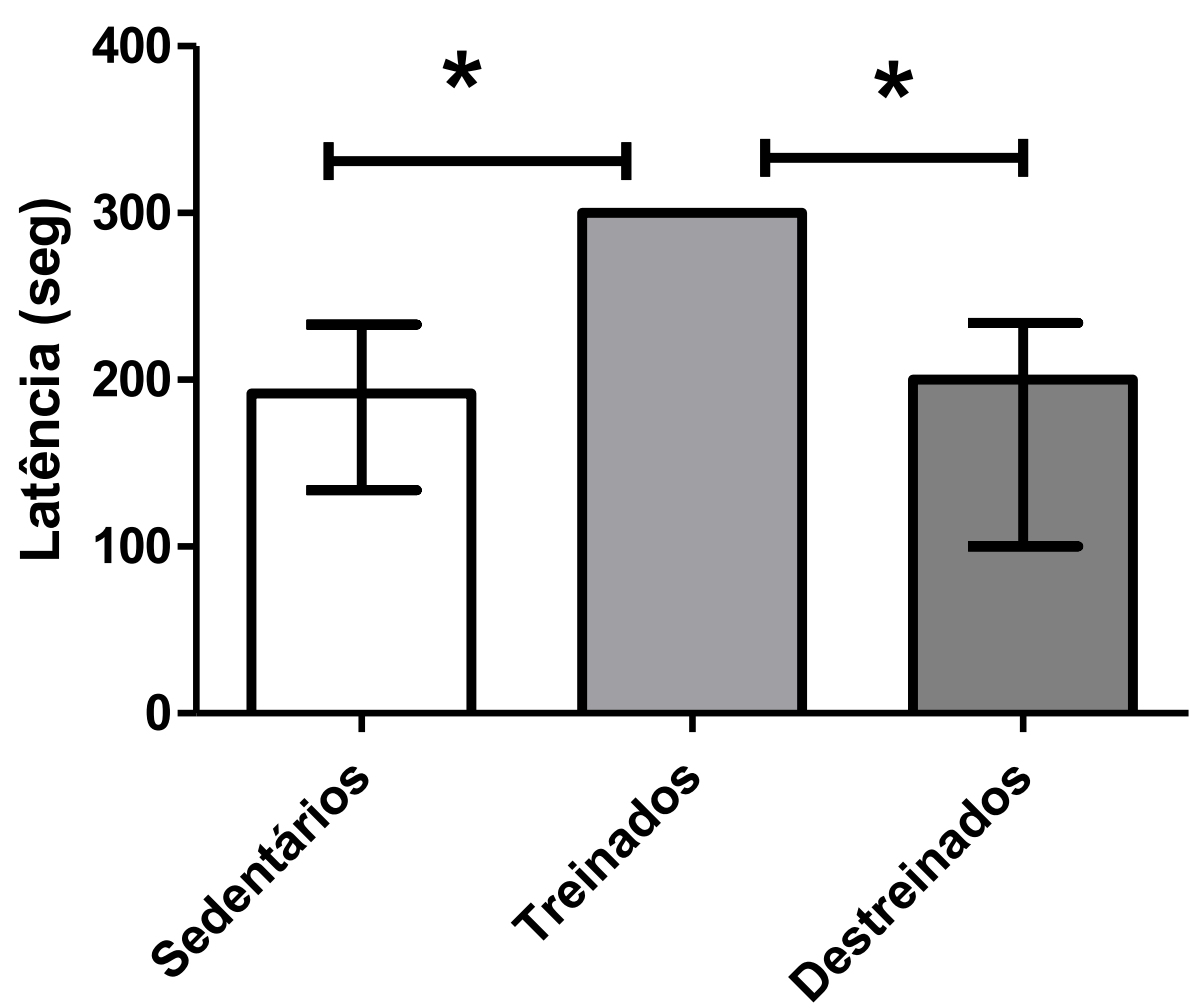

Comparação entre os grupos após o teste de evocação da memória avaliadas em equipamento de esquiva inibitória (Resteste II). *: P < 0,001 


\subsection{DETERMINAÇÃO DA DENSIDADE DA NEUROTROFINA BDNF EM HIPOCAMPO}

As áreas hipocampais dos diferentes grupos, foram seccionadas e utilizadas para medir a presença da neurotrofina BDNF pelo método de ensaio de imunoabsorção enzimática em placa de Elisa, apesar do discreto aumento da densidade de BDNF no hipocampo não houve diferença estatística significativa entre os grupos estudados.

Figura 8 - Determinação da densidade da neurotrofina BDNF.

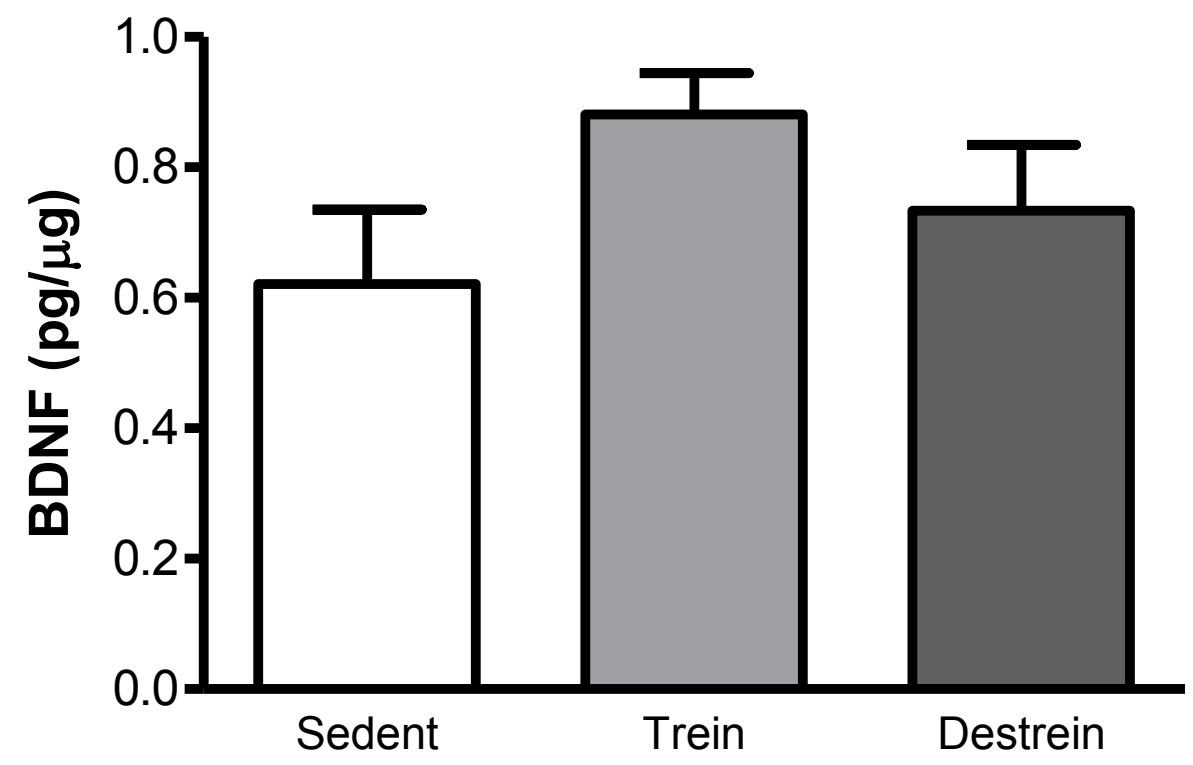

Comparação da densidade da presença da neurtrofina BDNF, pelo método de ensaio de imunoabsorção enzimática em placa de Elisa, Dados expressos em pg/pg de proteínas. 


\subsection{DETERMNAÇÃO DA DENSIDADE DO RECEPTOR ALFA 7 EM HIPOCAMPO}

A densidade do receptor nicotínico alfa7 foi determinada por western blotting a partir da concentração de proteína escolhida de $25 \mu \mathrm{g}$ ( figura 9A) nos diferentes grupos estudados. Não houve diferença estatística significativa entre os grupos avaliados.(grupos: $\mathrm{S}=$ sedentários, $\mathrm{D}=$ destreinados, $\mathrm{T}=$ treinados).

Figura 9 - Curva de análise da concentração do receptor nicotínico Alfa 7.
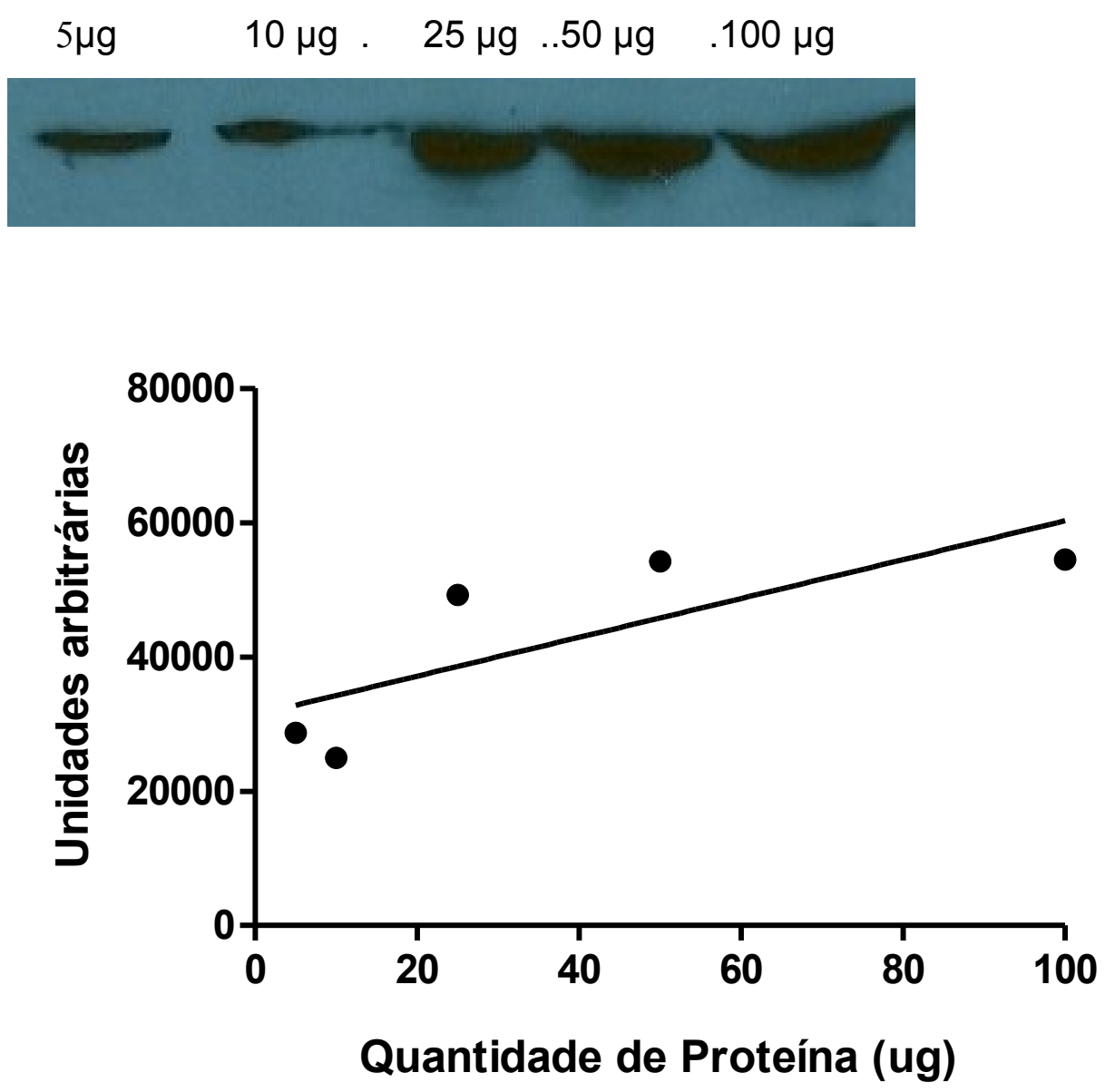

Concetração escolhida foi de $25 \mu \mathrm{g}$ para avaliar a densidade do receptor alfa 7 no hipocampo de camundongos fêmeas. 
Figura 10 - Determinação da densidade do receptor nicotínico Alfa 7.

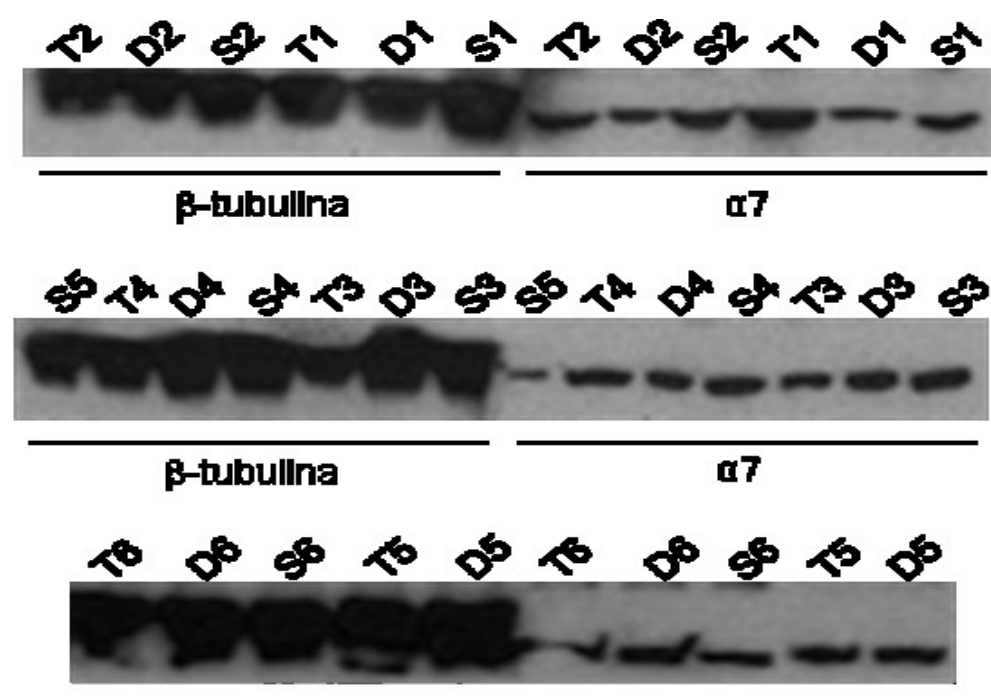

p-tubulina

$\mathbf{a 7}$

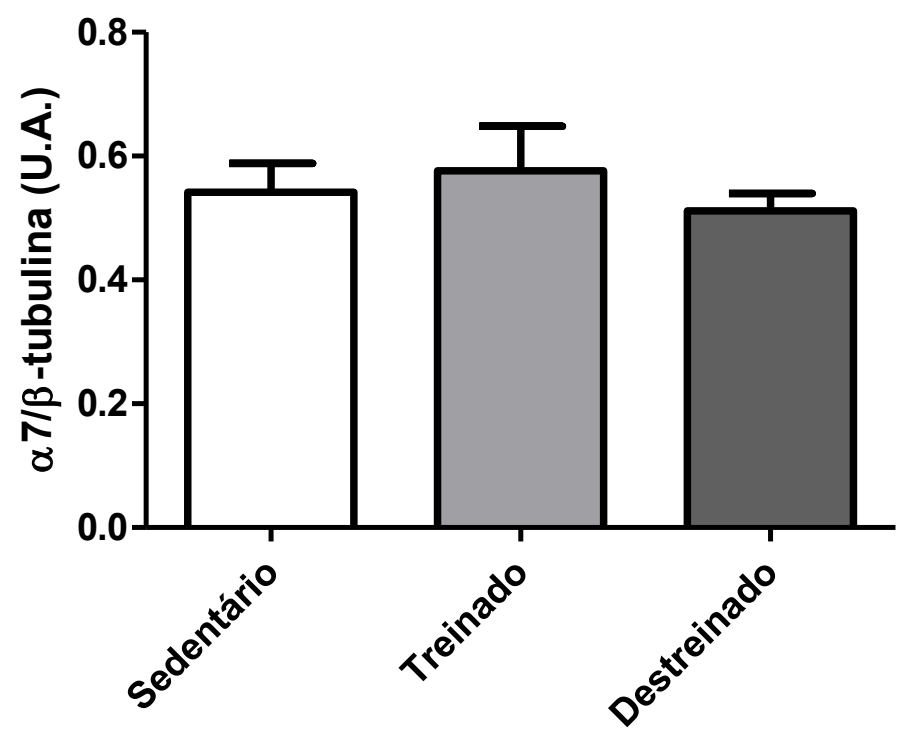

Comparação da densidade do receptor nicotínico Alfa 7 em hipocampo de camundongos fêmeas, dados estão expressados em unidades arbitrárias. 


\section{DISCUSSÃo}

A atividade física ocupa um importante papel na promoção da saúde, sendo, portanto, um alvo interessante para as políticas públicas. A Organização Mundial da Saúde (OMS) recomenda que "(...) os indivíduos adotem níveis adequados de atividade física durante toda a vida". No presente estudo, o protocolo de treinamento físico realizado em piscina conduz a um condicionamento robusto de alta performance (EVANGELISTA et al., 2003), semelhante ao treinamento de atletas.

Antes de iniciarmos a avaliação da memória, uma primeira avaliação da atividade motora foi realizada, pois se nesta fosse detectado qualquer problema na deambulação ou exploração vertical do animal, o mesmo teria que ser descartado do estudo, uma vez que o protocolo para avaliação da memória, bem como o protocolo de treinamento físico exigiriam deambulação e movimentação física adequadas dos animais. Neste trabalho nenhum animal apresentou problema em nenhum dos dois pontos avaliados, sendo todos os animais considerados aptos aos protocolos subsequentes. Da mesma forma, ao final do treinamento físico, nova avaliação da atividade motora foi realizada (Dado não demonstrado), onde foi verificado que todos os animais apresentaram deambulação e exploração semelhantes, independente do protocolo a que foram submetidos.

Analisamos o consumo de ração e água assim como o peso corporal dos animais a fim de avaliar possíveis diferenças entre os animais sedentários, os animais treinados e os animais destreinados que pudessem influenciar os resultados de memória obtidos. Os três grupos de animais apresentaram um consumo de ração entre 25 e 35 gramas por semana. Esses valores são considerados normais segundo o Manual de Normas Técnicas do Biotério do ICB-USP (2011). Não houve diferença significativa entre os grupos no consumo de ração. Os grupos estudados não apresentaram diferença no consumo de água durante as 6 semanas que estiveram em treinamento ou sedentarismo consumindo de 40 a $50 \mathrm{ml}$ por semana, por animal.

Além do consumo de ração e água, o ganho ponderal durante o tempo de observação foi avaliado onde se verificou que foi semelhante nos três grupos. Os animais sedentários e treinados provavelmente permaneceram com mesmo peso corporal, pois nos treinados há perda de massa gorda e aumento de massa magra. 
De fato, no dia que os animais foram mortos foi observado (visualmente) aumento de gordura visceral apenas nos animais sedentários.

A avaliação da memória de longa duração foi realizada utilizando o equipamento de esquiva inibitória. O teste foi realizado em 4 momentos diferentes a fim de avaliar possíveis alterações na memória em relação a execução de atividade física ou não. O primeiro momento foi chamado de sessão de aquisição onde os animais devem aprender a tarefa. Uma vez que a preferência por locais escuros é um comportamento nato de roedores, os animais passaram rapidamente para o compartimento escuro da caixa, onde levaram um leve estímulo elétrico. As sessões de avaliação da consolidação e evocação da memória foram realizadas 24 horas após a Sessão de Aquisição e, nesta, os animais apresentaram aumento da latência de permanência no lado claro da caixa, o que indicou que lembraram da tarefa aprendida no dia anterior.

Após os testes comportamentais iniciais, os animais foram divididos em "sedentários" e "treinados", conforme descrito em "material e métodos". Os animais do grupo "treinado" passaram por 4 semanas de treinamento intenso de natação e, após esse período, foi realizado novo teste de esquiva inibitória chamado de Reteste I. Neste teste foi avaliada a retenção da informação adquirida antes do início do treinamento pelos dois grupos. Os animais do grupo sedentário apresentaram latência menor, porém não significativa no Reteste I, indicando certo esquecimento da memória da informação adquirida quatro semanas antes. Por outro lado, os animais treinados apresentaram melhora da latência registrada antes do início do treinamento mostrando que o treinamento físico promoveu o aumento da memória de longa duração, corroborando com os dados demonstrados por nosso grupo anteriormente, que a atividade física é capaz de promover melhora da memória de animais, bem como alterações cerebrais significativas em áreas relacionadas à memória (ALBUQUERQUE et al., submetido).

Após o Reteste I, o grupo dos animais treinados foi dividido em dois grupos que, nas duas semanas seguintes passaram a ser submetidos a protocolos experimentais diferentes, sendo o grupo destinado ao destreinamento, passou a fazer 5 minutos de natação 3 vezes na semana, como os animais sedentários. Todos os grupos de animais passaram então pela última avaliação da memória, denominada Reteste II. 
Em contrapartida, os animais destreinados perderam a memória do teste. Dessa forma, podemos afirmar que o destreinamento físico altera a manutenção da memória de informações adquiridas antes e durante o treinamento. Essa observação vai de encontro com o observado com os efeitos do destreinamento físico, por duas semanas, no sistema periférico. De fato, há um declínio significativo na função cardiovascular e no potencial metabólico muscular em dias ou semanas após o destreinamento. Esse declínio está associado com uma redução significativa no pico de $\mathrm{VO}_{2}$ (MUJIKA; PADILLA, 2001). Embora um pico aumentado de $\mathrm{VO}_{2}$ e a bradicardia de repouso estejam relacionados com um melhor desempenho físico e melhor funcionamento cardiovascular, essas respostas são gradualmente perdidas quando o treinamento é descontinuado.

Por outro lado, já é conhecido que o treinamento físico aumenta a produção de neurotrofinas, como o BDNF (do inglês "brain-derived neurotrophic factor"), agindo como protetor das funções cognitivas. O BDNF tem sido considerado o maior candidato para a modulação dos efeitos da atividade física em processos, desde que essa neurotrofina foi correlacionada com a evocação da memória, (GÓMEZPALACIO-SCHJETNAN; ESCOBAR, 2013; LECKIE et al., 2012).O BDNF e outras neurotrofinas têm sido considerado fator chave na manutenção da potenciação de longa duração (LTP - Long Term Potentiation), o modelo biológico mais aceito para explicar a formação da memória de longa duração (KANDEL, 2001; PANG; LU, 2004). Nesse trabalho não foi observado um aumento significativo da densidade do BDNF no hipocampo dos animais do grupo treinado, em relação ao controle, porém Radak e colaboradores (2006) demonstraram que os níveis de BDNF aumentam significativamente após 8 semanas de treinamento intenso em piscina e diminuem, também significativamente, após 6 semanas de destreinamento. Possivelmente a razão pela qual o grupo treinado não apresentou um aumento significativo da densidade dessa neurotrofina no presente estudo foi porque os tempos de treinamento e destreinamento foram menores. Segundo Evangelista et al (2005) em 4 semanas de treinamento físico de alta intensidade, os animais já estão treinados e com 2 semanas de destreinamento os mesmos, apresentam perda dos benefícios cardiovasculares adquiridos, levando a nossa hipótese de que o mesmo aconteceria com os níveis da neurotrofina BDNF. 
Neste trabalho também foi investigado a participação do receptor alfa7 devido as evidências da sua participação em diversas atividades hipocampais e a participação do neurotransmissor acetilcolina do sistema colinérgico nos processos de memória. O sistema colinérgico é um dos sistemas que estão implicados na formação da memória em várias áreas do cérebro. (HUANG; KANDEL; LEVINE, 2008; ONDREJCAK et al., 2012). Neste contexto, há evidências para a participação do receptor nicotínico alfa7 em diversas atividades hipocampais. (MIELKE; MEALING, 2009), reconsolidação da memória (BOCCIA et al., 2010) e atenção sustentada (REZVANI et al., 2009; VIEL et al., 2012; YOUNG et al., 2007;). Além do mais, há registros de que o BDNF também regula e estabiliza a expressão do receptor nicotínico alfa7 (KAWAI et al., 2002; MASSEY; ZAGO; BERG, 2006; ZHOU et al., 2004), o que poderia ser outra via que correlaciona exercício físico com a evocação da memória, porém não foi verificada alteração significativa da densidade do receptor alfa7.

Em humanos, diversos estudos têm demonstrado que o exercício físico pode modular funções cognitivas e agir como potencial tratamento não-farmacológico para pacientes que tem alterações cognitivas, como a doença de Alzheimer, apesar dos mecanismos moleculares envolvidos ainda não serem claros (BROWN; PEIFFER; MARTINS, 2012). Além disso, muitos estudos utilizando modelos animais têm demonstrado efeitos benéficos da atividade física em processos cognitivos usando protocolos de exercícios distintos, como exercício espontâneo em roda de atividade e corrida em esteira ergométrica. Embora estes dois protocolos regulem a via BDNFTrKB no hipocampo, outras regiões do cérebro também podem ser ativadas por eles (LIU et al., 2009).

Por essas razões, são necessários mais estudos para determinar-se a importância do receptor nicotínico alfa 7 e a neurotrofina BDNF na manutenção da memória sobre o treinamento físico e identificar seus papéis. 


\section{CONCLUSÃO}

Após o período de 6 semanas, entre treinamento e destreinamento físico de camundongos fêmeas $\mathrm{C} 57 \mathrm{BI} / 6$ e determinação das densidades do receptor nicotínico alfa 7 e a neurotrofina BDNF, foi concluído no presente trabalho que:

O Treinamento físico de alta intensidade traz ganhos significativos para memória, que levam a uma melhora da qualidade de vida, assim como benefícios cardiovasculares e aumento do desempenho físico.

O Destreinamento físico traz perda significativa dos benefícios da memória, adquiridos ao longo de 4 semanas de treinamento físico de alta performance. Assim como acontece com os benefícios cardiovasculares, a memória adquirida retorna ao patamar do animal sedentário em apenas 2 semanas de descontinuamento do treinamento físico de alta intensidade.

Não houve alterações significativas da densidade do receptor alfa 7 do sistema colinérgico e a neurotrofina BDNF, após duas semanas de destreinamento físico. 


\section{REFERÊNCIAS*}

ANTUNES, H. K. M; SANTOS, R. F.; MELLO, M. T.; BUENO, O. F. A. Memória e exercício físico. In: MELLO, M. T.; TUFIK, S. Atividade física, exercício físico e aspectos psicobiológicos, Rio de Janeiro: Ed Guanabara-Koogan, p. 140, 2004.

ARIAS, H. R. Topology of ligand binding sites on the nicotinic acetylcholine receptor. Brain Res. Rev, v. 25, p. 133-191, 1997.

BOCCIA, M. M.; BLAKE, M. G.; KRAWCZYK, M. C.; BARATTI, C. M. Hippocampal alpha7 nicotinic receptors modulate memory reconsolidation of an inhibitory avoidance task in mice. Neuroscience, v. 171, p. 531-543, 2010.

BROWN, B. M.; PEIFFER, J. J.; MARTINS, R. N. Multiple effects of physical activity on molecular and cognitive signs of brain aging: can exercise slow neurodegeneration and delay Alzheimer's disease? Mol. Psychiatry, p. 162, 2012.

BUCKINGHAM, S. D.; JONES, A. K.; BROWN, L. A.; SATTELLE, D. B. Nicotinic acetylcoline receptors signaling: roles in Alzheimer's disease and amyloid protection. Pharmacol. Rev. v. 61, p. 39-61, 2009.

CARTER, J. B.; BANISTER, E. W.; BLABER, A. P. Effect of endurance exercise on autonomic control of heart rate. Sports Medicine, v. 33, p. 33-46, 2003.

CARVALHO, T.; NÓBREGA, A. C. L.; LAZZOLI, J. K.; MAGNI, J. R. T.; REZENDE, L.; DRUMMOND, F. A.; OLIVEIRA, M. A. B; DE ROSE, E. H.; ARAÚJO, C. G. S.de; TEIXEIRA, J. A. C. Posição oficial da Sociedade Brasileira de Medicina do Esporte: atividade física e saúde. In: Rev Bras Med Esport, v. 2, p. 4, 1996.

CLEMENTI, F.; FORNASARI, D.; GOTTI, C. Neuronal nicotinic acetylcholine receptors: from structure to therapeutics. TiPS, v. 21, p. 35-37, 2000.

DANI, J. A; BERTRAND, D. Nicotinic acetylcholine receptors and nicotinic cholinergic mechanisms of the central nervous system. Annu. Rev. Pharmacol. Toxicol. v. 47, p. 699-729, 2007.

DE ANGELIS, K.; WICHI, R. B.; JESUS, W. R.; MOREIRA, E. D.; MORRIS, M.; KRIEGER, E. M.; IRIGOYEN, M. C. Exercise training changes autonomic cardiovascular balance in mice. Journal of Applied Physiology, v. 96, p. 21742178, 2004.

DE MATTOS PIMENTA, M. A. Cognição e envelhecimento. Ed. Porto Alegre, 2009.

*De acordo com:

ASSOCIAÇÃO BRASILEIRA DE NORMAS TÉCNICAS. NBR 6023: informação e documentação: referências: elaboração. Rio de Janeiro, 2002. 
EVANGELISTA, F. S; MARTUCHI, S. E. D.; NEGRÃO, C. E.; BRUM, P. C. Durationcotrolled swimming exercise tranning induces cardiac hypertrophy in mice. Brazilian Journal of Medical and Biological Researches, v. 36, p. 1751-1759, 2003.

EVANGELISTA, F. S.; MARTUCHI, S. E. D.; NEGRÃO, C. E.; BRUM, P. C. Loss of resting bradycardia with detraining is associated with intrinsic heart rate changes. Braz. J. Med. Biol. Res. v. 38, p. 1141-1146, 2005.

GAUTHIER, S. Advances in pharmacotherapy of Alzheimer's disease. CMAJ, v. 166, n. 5, p. 616-623, 2002.

GAZZANIGA, M. S; HEATHERTON, T. F. Ciência psicológica: mente, cérebro e comportamento. 2. ed. Porto Alegre: Artmed, p. 624, 2005

GÓMEZ-PALACIO-SCHJETNAN, A.; ESCOBAR, M. L. Neurotrophins and Synaptic Plasticity. Curr. Top. Behav. Neurosci, 2013.

HAKE, A. M.; FARLOW, M. R. New concepts in the drug therapy of Alzheimer's disease. Expert. Opin. Pharmacother. v. 2, n. 12, p. 1975-1983, 2001.

HANSEN, A. L.; JOHNSEN, B. H.; SOLLERS I. J. J.; STENVIK, K.; THAYER, J. F. Heart rate variability and its relation to prefrontal cognitive function: the effects of training and detraining. Eur. J. Appl. Physiol. v. 93, p. 263-272, 2004.

HOGAN, D. B.; PATTERSON, C. Treatment of Alzheimer's disease and other dementias - review and comparison of the cholinesterase inhibitors. Can. J. Neurol. Sci., v. 29, p. 306-314, 2002.

HUANG Y, KANDEL E. R, LEVINE A. Chronic nicotine exposure induces a longlasting and pathway-specific facilitation of LTP in the amygdala. Learn. Mem. v. 15, p. 603-610, 2008.

IZQUIERDO, I. Memória. Porto Alegre: Artmed, 2002.

IZQUIERDO, I. Memória. 2. ed. Porto Alegre: Artmed, 2011.

IZQUIERDO, I.; MEDINA, J. H. Memory formations, the sequence of biochemical events in the hippocampus and its connections to activity in other brain structures. Neurobiol. Learn. Mem. v. 68, p. 285-316, 1997.

KANDEL, E. R. The molecular biology of memory storage: a dialogue between genes and synapses. Science, v. 294, p. 1030-1038, 2001.

KATZUNG, B. G. Farmacologia básica e clínica. 10. ed., Porto Alegre: AMGH Editora, 2010.

KAWAI, H., ZAGO, W., BERG, D. K.. Nicotinic alpha 7 receptor clusters on hippocampal GABAergic neurons: regulation by synaptic activity and neurotrophins. J. Neurosci., v. 22, n. 18, p. 7903-7912, 2012 
KEMI, O. J.; HARAM, P. M.; WISLOFF, U.; ELLINGSEN, O. Aerobic fitness is associated with cardiomyocyte contractile capacity and endothelial function in exercise training and detraining. Circulation, v. 109, p. 2897-2904, 2004.

LENT, R. Cem bilhões de neurônios: conceitos fundamentais de neurociências. São Paulo: Ed Atheneu, 2004. p. 698

LECKIE, R. L.; WEINSTEIN, A. M; HODZIC, J. C; ERICKSON, K. I. Potential moderators of physical activity on brain health. J. Aging Res., v. 2012, p. 948-981, 2012.

LIU, X; XU, Y; JIANG, S; CUI, D; QIAN, Y; JIANG, K. Family-based association study between brain-derived neurotrophic factor gene and major depressive disorder of Chinese descent. Psychiatry Res., v. 169, n. 2, p. 169-172, 2009.

MASSEY, K. A; ZAGO, W; BERG, D. K. BDNF up-regulates alpha7 nicotinic acetylcholine receptor levels on subpopulations of hippocampal interneurons. Mol. Cell Neurosci., v. 33, n. 4, p. 381-388, 2006.

McAULEY, E; RUDOLPH, D. Physical activity, Aging and Phychological. Well-Being, v. 3, p. 67-96, 1995.

McGAUGH, J. L. Involvement of hormonal and neuromodulatory systems in the regulation of memory storage. Annu. Rev. Neurosci., v. 12, p. 255-87, 1989.

McGEHEE, D. S; ROLE, L. W. Neurobiology: memories of nicotine. Nature, v. 383, n. 6602, p. 670-671, 1996.

McKINNEY, M; JACKSONVILLE, M. C. Brain cholinergic vulnerability: relevance to behavior and disease. Biochem. Pharmacol, v. 70, p. 1115-1124, 2005.

MESULAM, M. The cholinergic lesion of Alzheimer's disease: Pivotal factor or side show? Learning \& Memory, v. 11, n. 1, p. 43-49, 2004.

MIELKE, J. G.; MEALING, G. A. R. Cellular distribution of the nicotinic acetylcholine receptor a7 subunit in rat hippocampus. Neurosci. Res, v. 65, p. 296-306, 2009.

MUJIKA, I; PADILLA, S. Cardiorespiratory and metabolic characteristics of detraining in humans. Medicine and Science in Sports and Exercise, v. 33, p. 413-421, 2001.

NADEL, L; HARDT, $O$. Update on memory systems and processes. Neuropsychopharmac. Reviews, v. 36, p. 251-273, 2011.

NASHMI, R; LESTER H. A. CNS localization of neuronal nicotinic receptors. J. Mol. Neurosci, v. 30, n. 1-2, p. 181-184, 2006.

ONDREJCAK, T.; WANG, Q.; KEW, J. N.; VIRLEY, D. J.; UPTON, N.; ANWYL, R.; ROWAN, M. J. Activation of $\alpha 7$ nicotinic acetylcholine receptors persistently enhances hippocampal synaptic transmission and prevents $A ß$-mediated inhibition of LTP in the rat hippocampus. Eur. J. Pharmacol, v. 677, n. 1-3, p. 63-70, 2012. 
ORGANIZAÇÃO MUNDIAL DA SAÚDE. Global strategy on diet, physical activity and health (EG/OMS). Fifty-seventh world health assembly. Disponível em: <http://www.who.int/gb/ebwha/pdf_files/WHA57/A57_R17-en.pdf>. Acesso em: 21 fev. 2013.

PANG, P. T.; LU, B. Regulation of late-phase LTP and long-term memory in normal and aging hippocampus: role of secreted proteins tPA and BDNF. Ageing. Res. Rev., v. 3, n. 4, p. 407-430, 2004.

RADAK, Z.; TOLDY, A.; SZABO, Z.; SIAMILIS, S.; NYAKAS, C.; SILYE, G.; JAKUS, J.; GOTO, S. The effects of training and detraining on memory, neurotrophins and oxidative stress markers in rat brain. Neurochem. Intern, v. 49, p. 387-392, 2006.

RANG, H. P.; DALE, M. M.; RITTER, J. M.; FLOWER, R. J. Farmacologia. 6. ed. Rio de Janeiro: Elsevier, 2008.

REZVANI, A. H; KHOLDEBARIN, E; BRUCATO, F. H; CALLAHAN, P. M; LOWE, D. A; LEVIN, E. D. Effect of R3487/MEM3454, a novel nicotinic a7 receptor partial agonist and 5-HT3 antagonist on sustained attention in rats. Prog. Neuropsychopharmacol. Biol. Psychiatry, v. 33, p. 269-275, 2009.

ROLE, L. W.; BERG, D. K. Nicotinic receptors in the development and modulation of CNS synapses. Neuron, v. 16, n. 6, p. 1077-1085, 1996.

SANTOS, D. L.; MILANO, M. E.; ROSAT, R. Exercício físico e memória. Rev. Paul. Educ. Física, v. 12, n. 1, p. 95-106, 1998.

SEGOVIA, G.; ARCO, A. D.; MOTA, F. Environmental enrichment, prefrontal cortex, stress and aging of the brain. J. Neural Transm., v. 116, p. 1007-1016, 2009.

SILVERTHORN, D. U. Fisiologia humana: uma abordagem integrada. 2. ed. São Paulo: Ed. Manole, 2003. p. 816.

SQUIRE, L. R.; KANDEL E. R. Memória da mente às moléculas. Porto Alegre: Artmed, 2003.

SIU, P. M.; BRYNER, R. W.; MARTYN, J. K.; ALWAYS, S. E. Apoptotic adaptations from exercise training in skeletal and cardiac muscles. FASEB J., v. 18, p. 11501152, 2004.

VANCINI, R. L.; LIRA, C. A. B.; ABOULAFIA, J; NOUAILHETAS, V. L. A. Influência do exercício sobre a produção de radicais livres. Rev.Bras. Ativ. Fís. Saúde, v. 10, n. 2, p. 47- 58, 2005.

VIEL, T. A.; CAETANO, A. L.; NASELLO, A. G.; LANCELOTTI, C. L.; NUNES, V. A.; ARAÚJO, M. S.; BUCK, H. S. Increases of kinin B1 and B2 receptors binding sites after brain infusion of amyloid-beta 1-40 peptide in rats. Neurobiol. Ageing, v. 29, n. 12, p. 1805-1814, 2008. 
VIEL, T. A.; CAETANO, A. L.; ALBUQUERQUE, M. S.; ARAUJO, M. S.; BUCK, H. S. Chronic infusion of amyloid- $\beta$ peptide and sustained attention altered $\alpha 7$ nicotinic receptor density in the rat brain. Curr. Alzheimer. Res, v. 9, n. 10, p. 1210-1220, 2012.

WEVERS, A.; SCHRÖDER, H. Nicotinic Acetylcoline receptors in Alzheimer's disease. J. Alzheimers Dis, v. 1, p. 207-219, 1999.

YOUNG, J. W.; CRAWFORD, N.; KELLY, J. S.; KERR, L. E.; MARSTON, H. M.; SPRATT, C.; FINLAYSON, K.; SHARKEY, J. Impaired attention is central to the cognitive deficits observed in alpha 7 deficient mice. Eur. Neuropsychopharmacol, v. 17, p. 145-155, 2007.

ZHOU, X.; NAI, Q.; CHEN, M.; DITTUS, J. D.; HOWARD, M. J.; MARGIOTTA, J. F. Brain-derived neurotrophic factor and TrkB signaling in parasympathetic neurons: relevance to regulating alpha7-containing nicotinic receptors and synaptic function. $\mathbf{J}$. Neurosci., v. 24, n. 18, p. 4340-4350, 2004. 